\title{
Improvement of Snow Depth Reproduction in Japanese Urban Areas by the Inclusion of a Snowpack Scheme in the SPUC Model
}

\author{
Rui ITO \\ Japan Meteorological Business Support Center, Tsukuba, Japan \\ Meteorological Research Institute, Japan Meteorological Agency, Tsukuba, Japan \\ Toshinori AOYAGI \\ Japan Meteorological Agency, Tokyo, Japan \\ Naoto HORI \\ Yamagata Meteorological office, Japan Meteorological Agency, Yamagata, Japan \\ Mitsuo OH'IZUMI \\ Meteorological college, Japan Meteorological Agency, Kashiwa, Japan \\ Hiroaki KAWASE \\ Meteorological Research Institute, Japan Meteorological Agency, Tsukuba, Japan \\ Koji DAIRAKU \\ National Research Institute for Earth Science and Disaster Resilience, Tsukuba, Japan \\ Naoko SEINO, and Hidetaka SASAKI \\ Meteorological Research Institute, Japan Meteorological Agency, Tsukuba, Japan \\ (Manuscript received 30 November 2017 in final form 27 July 2018)
}

\begin{abstract}
Accurate simulation of urban snow accumulation/melting processes is important to provide reliable information about climate change in snowy urban areas. The Japan Meteorological Agency operates a square prism urban canopy (SPUC) model within their regional model to simulate the urban atmosphere. However, presently, this model takes no account of snow processes. Therefore, in this study, we enhanced the SPUC by introducing a snowpack scheme, and assessed the simulated snow over Japanese urban areas by comparing the snow depths from the enhanced SPUC and those from a simple biosphere (iSiB) model with the observations. Snowpack schemes based on two approaches were implemented. The diagnostic approach (sSPUCdgn) uses empirical factors for snow temperature and melting/freezing amounts and the Penman equation for heat fluxes, whereas the prognostic
\end{abstract}

Corresponding author: Rui Ito, Japan Meteorological Business Support Center, 1-1 Nagamine, Tsukuba, Ibaraki 305-

0052, Japan

E-mail: rui.ito@jmbsc.or.jp

J-stage Advance Published Date: 24 August 2018

CThe Author(s) 2018. This is an open access article published by the Meteorological Society of Japan under a Creative Commons Attribution 4.0 International (CC BY 4.0) license (http://creativecommons.org/license/by/4.0). 
approach (sSPUCprg) calculates snow temperatures using heat fluxes estimated from bulk equations. Both snowpack schemes enabled the model to accurately reproduce the seasonal variations and peaks in snow depth, but it is necessary to use sSPUCprg if we wish to consider the physical processes in the snow layer. Compared to iSiB, sSPUCprg resulted in a good performance for the seasonal variations in snow depth and the error fell to $20 \%$. While iSiB overestimated the snow depth, a cold bias of over $1{ }^{\circ} \mathrm{C}$ appeared in the daily mean temperature, which can be attributed to excessive decreases in the snow surface temperature. sSPUCprg reduces the bias by a different calculation method for the snow surface temperature and by including heated building walls without snow; consequently, the simulated snow depth is improved. With an increase in the correlation coefficient, sSPUCprg generated a relationship between the seasonal variations in snowfall and snow depth close to the observed relationship. Therefore, the simulation accuracy of snowfall becomes more crucial for simulating the surface snow processes precisely by using the enhanced SPUC.

Keywords snowpack; urban canopy; model development; regional model

\section{Introduction}

Dynamical and statistical downscaling techniques are frequently used to examine how global climate change influences climate at the regional scale. Highresolution regional atmospheric models represent topography more realistically, and can resolve urban areas. Therefore, there has been an increase in the number of numerical modeling studies of the urban climate under a future climate and the relationship between urbanization and global climate change (Lemonsu et al. 2013; Argüeso et al. 2014; Hamdi et al. 2014, 2015; Kusaka et al. 2016).

Urban canopy models have been developed to represent the characteristic energy and water balance in urban areas that relatively high-resolution models can resolve (e.g., Masson 2000; Kusaka et al. 2001; Martilli et al. 2002; Dupont et al. 2004; Kondo et al. 2005). There have also been numerous studies of urban effects on the regional atmospheric environment using regional atmospheric models coupled with the urban models (e.g., Adachi et al. 2014; Kusaka et al. 2014; Lin et al. 2016; Nemunaitis-Berry et al. 2017). However, studies of urban hydrology have focused on precipitation around urban areas, with few studies considering snow accumulation (but see Valeo and Ho 2004).

Järvi et al. (2014) pointed out the need for suitable snow modeling for simulations of urban climate in cold areas; however, only a few studies have focused on urban snow modeling, despite the urban climate in these areas being particularly sensitive to climate change at regional and global scales. Mori and Sato (2015) presented a quantitative discussion regarding the effect of a snowy urban canopy on the thermal environment in urban areas. They stated that snow cover in urban areas is comparably important to anthropogenic heat. Järvi et al. (2014) enhanced an existing model, the Surface Urban Energy and Water balance Scheme (SUEWS; Järvi et al. 2011), such that it could represent the processes of snow accumulation and melting. SUEWS is a simplified model that calculates energy and water exchange processes within, and between, grid cells for several types of surfaces, including urban. The validity of the enhanced SUEWS for the energy budget in cold-climate cities has been discussed by Järvi et al. (2014) and Karsisto et al. (2016). Järvi et al. (2014) referred to the urban snow model developed by Valeo and Ho (2004) as a potential approach to model enhancement. Shui et al. (2016) proposed another model that deals with the snowpack on urban surfaces, but it cannot simulate seasonal variations such as snow accumulation and melting.

A square prism urban canopy (SPUC) model (Aoyagi and Seino 2011) treats the urban canopy as a single layer of buildings shaped as square prisms. The model is run on an operational non-hydrostatic model by the Japan Meteorological Agency (JMA-NHM; Saito et al. 2006, 2007), especially on the model for urban heat island monitoring and on a non-hydrostatic regional climate model (NHRCM; Sasaki et al. 2008). The original SPUC model represents snow as liquid precipitation and cannot simulate snow accumulation. Thus, it cannot represent daily and seasonal variations in snow cover in urban areas.

In Japan, the regional atmospheric model with a $5-\mathrm{km}$ grid spacing begins to resolve not only large cities, such as the Tokyo Metropolitan area, but also medium and small cities, such as those located in the snowy areas of northern Japan. Snowfall occurs over these cities every year, and heavy snowfall sometimes has a major impact on human activity. Seasonal varia- 
tion is also important from the viewpoint of snowmelt floods and the timing of meltwater supply. Bengtsson and Westerström (1992) observed snow cover around a city in northern Sweden and revealed that the time series of snow melting and consequent runoff processes in urban areas differ from those in rural areas. Therefore, sophisticated modeling of snow cover in urban areas is important for understanding snowy urban climates. In addition, patterns of snow cover are expected to change considerably in Japan as global warming proceeds (e.g., Kawase et al. 2015, 2016). Highly accurate representations of snow accumulation and melting processes under the present climate will be necessary if we are to generate more accurate projections of future patterns of snow cover in snowy areas including urban areas.

The aim of this study was to introduce an urban snowpack scheme into the SPUC model and to verify the accuracy of the snow simulated by the enhanced SPUC in Japanese urban areas. The verification was carried out in two steps. First, we focused on the performance of the enhanced SPUC itself by evaluating simulated parameters related to the snowpack in the snow layer using offline experiments. Second, we compared the climatological seasonal variations in the snow cover simulated by the enhanced SPUC in the NHRCM with observational data obtained from the JMA, and investigated the behavior of the enhanced SPUC in a regional climate model and its usefulness. This study is the first stage of improving our understanding of past urban climates and projecting future urban climates throughout the year with high accuracy.

\section{Outline of urban snowpack scheme}

We used two approaches to estimate snow accumulation and melting: diagnostic estimation and prognostic estimation. The simulated snowpack is a single layer, and snow accumulation is estimated from the snow water equivalent. A full or partial snowpack can occur on an urban surface.

Figures 1 and 2 show schematic diagrams of the energy and water balances, respectively, on a snowcovered urban surface. The energy balance can be written as

$$
Q^{*}=Q_{H}+Q_{E}-Q_{P}-Q_{G}+\Delta Q_{S}+Q_{M} .
$$

Here, the net radiation $\left(Q^{*}\right)$, the sensible heat $\left(Q_{H}\right)$, the latent heat $\left(Q_{E}\right)$, the heat released from liquid precipitation $\left(Q_{P}\right)$, and the conductive heat from the urban surface under the snow layer $\left(Q_{G}\right)$ are the energy inputs to the snowpack. The heat storage change $\left(\Delta Q_{S}\right)$

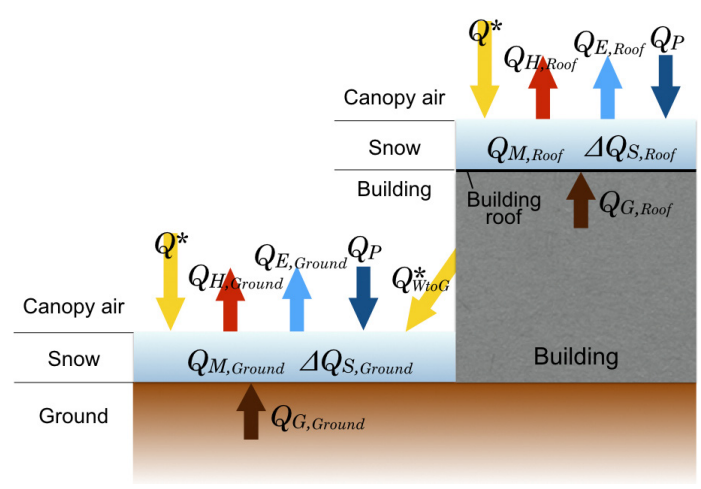

Fig. 1. Schematic representation of the energy balance on an urban surface covered by snow.

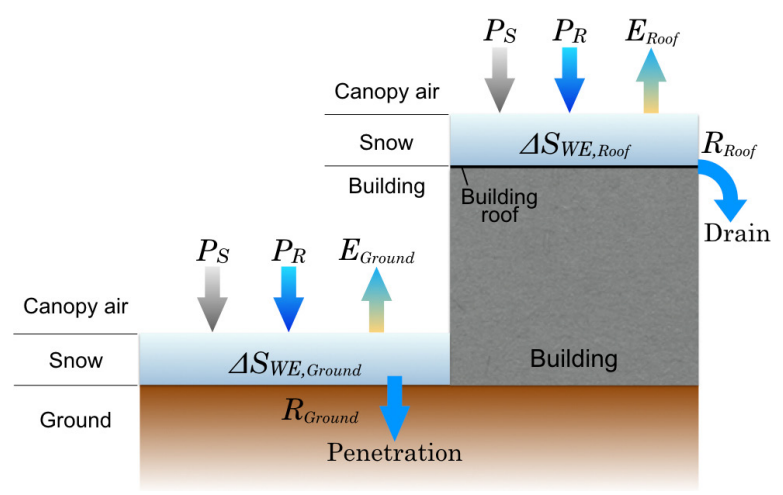

Fig. 2. Schematic representation of the water balance on an urban surface covered by snow.

and the snowmelt latent heat $\left(Q_{M}\right)$ are the energy stored and used in the snow layer. The radiation $Q^{*}$ is from the radiation balance between the snowy surface and the atmosphere above the canopy. The net radiation from the walls to the snowy ground $Q^{*}{ }_{W t o G}$ is also added, especially on the ground around a building. The time variation of the snow water equivalent $S_{W E}$ is expressed as

$$
S_{W E}(t+\Delta t)=S_{W E}(t)+\left(P_{S}+P_{R}-E-R\right) \Delta t,
$$

where $t$ is time, $P_{S}$ is the solid precipitation rate, $P_{R}$ is the liquid precipitation rate, $E$ is the evaporation rate from the snow surface, and $R$ is the outflow of liquid precipitation and snow melting.

A summary of the snow processes considered by each approach is given in Table 1 , and that of the notation used for each process is given in Appendix A. The two schemes are described in detail below. 
Table 1. Snow processes included in each scheme.

\begin{tabular}{|c|c|c|c|}
\hline & Diagnostic approach & Prognostic approach & $\mathrm{iSiB}$ \\
\hline Land scheme & \multicolumn{2}{|c|}{ SPUC } & $\mathrm{iSiB}$ \\
\hline Number of snow layer & \multicolumn{2}{|l|}{1} & 3 \\
\hline Snow temperature change & $\begin{array}{l}\text { Estimate from } \Delta Q_{S} \\
\text { snow density and depth }\end{array}$ & $\begin{array}{l}\text { Estimate from } \\
Q_{n e t} \text { and } S_{W E}\end{array}$ & $\begin{array}{l}\text { Heat conduction with a thermal conduc- } \\
\text { tivity depending on snow bulk density }\end{array}$ \\
\hline Snow albedo aging & \multicolumn{2}{|c|}{$\begin{array}{l}\text { Linear }\left(T_{a} \geq 0\right) \\
\text { Exponential }\left(T_{a}<0\right)\end{array}$} & Linear \\
\hline Density of fresh snow & \multicolumn{2}{|c|}{ Constant } & Consideration of wind and air temperature \\
\hline Densification & \multicolumn{2}{|c|}{ Exponentially aging with time } & Compactive viscosity \\
\hline Melting and freezing & $\begin{array}{l}\text { Diagnostic using } \\
\text { melting/freezing factors }\end{array}$ & $\begin{array}{l}\text { Estimate from } S_{W E} \\
\text { and snow temp. }\end{array}$ & Estimate from $S_{W E}$ and snow temp. \\
\hline Sensible and latent heat fluxes & Penman method & Bulk method ${ }^{1}$ & Bulk method ${ }^{2}$ \\
\hline
\end{tabular}

1 Deardorff (1978) and Beljaars and Holtslag (1991) for bulk coefficients.

2 Beljaars and Holtslag (1991) for bulk coefficients.

\subsection{Diagnostic approach}

The diagnostic approach has the advantage of low computational cost and easy model tuning because of the usage of empirical parameters. The snowpack scheme with the diagnostic approach is based on the equations in Järvi et al. (2014). We describe here only the modifications to Järvi et al. (2014) that were made when we introduced the scheme into SPUC. More details of the scheme are given in Appendix B.

\section{a. Heat storage and melting latent heat}

The heat storage change in the snow layer, $\Delta Q_{S}$, and snowmelt latent heat, $Q_{M}$, are diagnosed from the net radiation and the canopy air temperature. The heat storage change $\Delta Q_{S}$ is estimated statistically from the net radiation $Q^{*}$ using the objective hysteresis model (OHM; Grimmond et al. 1991):

$$
\Delta Q_{S}=a_{1} Q^{*}+a_{2} \frac{\Delta Q^{*}}{\Delta t} .
$$

Here, the first term is the radiative heating and cooling and the second term indicates the hysteresis term of the heating and cooling. $\Delta t$ is a time step, and $a_{1}$ and $a_{2}$ are site-dependent parameters in the OHM. Grimmond et al. (1991) and Järvi et al. (2014) proposed a third term with an additional parameter $a_{3}$. We, however, omit this term because it represents the energy source from the ground below and we have already included the alternative term $Q_{G}$ in our diagnostic balance. The energy $Q_{G}$ is calculated after Chen and Dudhia (2001):

$$
Q_{G}=K_{S} \frac{T_{S}-T_{G}}{d_{S}}
$$

where $K_{S}$ is the thermal diffusivity for snow, $T_{S}$ is the snow temperature, $T_{G}$ is the internal temperature of the soil or roof, and $d_{S}$ is the snow depth. $K_{S}$ is estimated after Yamazaki (2001).

The latent heat associated with melting or freezing, $Q_{M}$, is calculated using the snow melting and freezing amount $M$,

$$
Q_{M}=\frac{\rho_{w} L_{F} M}{\Delta t}
$$

with water density $\rho_{w}$ and latent heat of fusion $L_{F}$.

\section{b. Sensible and latent heat fluxes}

Except for the sensible and latent heat fluxes, each energy is estimated as outlined above. The residual energy in the heat budget is released as the total of sensible heat flux $\left(Q_{H}\right)$ and latent heat flux $\left(Q_{E}\right)$ from the snow surface,

$$
Q_{H}+Q_{E}=Q^{*}+Q_{P}+Q_{G}-\Delta Q_{S}-Q_{M} .
$$

Each of the fluxes is calculated using the Penman equation:

$$
\begin{aligned}
Q_{H} & =\tilde{Q}-Q_{E}, \\
Q_{E} & =\frac{s \tilde{Q}+\rho c_{p} c_{q} U_{a}\left[q_{s a t}\left(T_{a}\right)-q_{a}\right]}{s+\gamma},
\end{aligned}
$$


where $\tilde{Q}=Q^{*}+Q_{P}+Q_{G}-\Delta Q_{S}-Q_{M}$.

Here, $s$ is the gradient of saturation specific humidity with respect to the temperature over ice, $\gamma$ is the psychrometric constant, $\rho$ is the air density, $c_{p}$ is the specific heat of air, $c_{q}$ is a bulk coefficient for the specific humidity flux, $U_{a}$ is the wind velocity in the canopy, $q_{\text {sat }}\left(T_{a}\right)$ is the saturated specific humidity at the canopy air temperature $\left(T_{a}\right)$, and $q_{a}$ is the specific humidity. Here, the coefficient $c_{q}$ is estimated from the wind velocity as described by Deardorff (1978).

\section{c. Snow melting and freezing}

The snow melting and freezing, $M$, is estimated as proportional to the flux $\left(Q^{*}\right)$ and temperature $\left(T_{a}\right)$ :

$$
M= \begin{cases}\max \left(a_{r} Q^{*}, 0\right)+a_{t} T_{a} & T_{a} \geq 0 \\ a_{f} T_{a} & T_{a}<0,\end{cases}
$$

with factors for radiation melt $a_{r}$ and temperature melt $a_{t}$ and a factor for freezing $a_{f}$. When the temperature exceeds $0^{\circ} \mathrm{C}$, the radiation and heat flux associated with air temperature are assumed to be used to drive the melting, which differs from the scheme in Järvi et al. (2014).

\subsection{Prognostic approach}

The prognostic approach is more consistent with the physics than is the diagnostic approach, although the bulk coefficients for sensible and latent heat fluxes are not completely established. Although the diagnostic approach is simple and easy to use, it has limitations: the heat storage is diagnosed only by the net radiation and is very sensitive to the fixed parameters $a_{1}$ and $a_{2}$, as well as to the melting and freezing rates $\left(a_{r}, a_{t}\right.$, and $a_{f}$ ) that must be adjusted to the target area, and when $T_{a} \geq 0$, melting can occur even at snow temperatures below $0^{\circ} \mathrm{C}$. Due to the fixed parameters and given rates, the heat storage $Q_{S}$ and snowmelt latent heat $Q_{M}$ can be inconsistent with the observations. Additionally, substantial perturbations can arise in the sensible and latent heat fluxes that are implied from the residual of the energy balance. Therefore, we modified the diagnostic approach for heat storage and snow melting/freezing in the snow layer, and instead estimated them using the time variation of snow temperature in a prognostic approach.

We used the bulk method for the estimation of the sensible and latent heat fluxes. As a consequence, the heat storage and heat used for melting/freezing can be estimated as the residuals of other energies as below:

$$
Q_{n e t} \equiv \Delta Q_{S}+Q_{M}=Q^{*}+Q_{P}+Q_{G}-Q_{H}-Q_{E} .
$$

\section{a. Sensible and latent heat fluxes}

We changed the calculation of the sensible and latent heat fluxes from the Penman method to the bulk method:

$$
\begin{aligned}
& Q_{H}=\rho c_{p} C_{h} U_{a}\left(T_{S}-T_{a}\right), \\
& Q_{E}=\rho L_{F} \beta C_{q} U_{a}\left[q_{\text {sat }}\left(T_{S}\right)-q_{a}\right],
\end{aligned}
$$

where $C_{h}$ and $C_{q}$ are the bulk coefficients for sensible and latent heat fluxes, respectively, and $\beta$ is the evaporation efficiency from the surface to the air. We followed Beljaars and Holtslag (1991) for the bulk coefficient between the lowest atmospheric layer in the model and the canopy space and between the canopy space and the ground covered by snow, and used the average of the coefficients in Beljaars and Holtslag (1991) and Deardorff (1978) between the canopy space and the snow-covered roof or wall. The bulk coefficients were tuned by multiplying them with parameters chosen to be close to the bulk coefficients in Kondo (1975) and Kondo and Yamazawa (1986). The tuning parameters for the bulk coefficient were specified as $K_{E}$ and $K_{H}$ (see Section 3.2).

\section{b. Heat storage}

The heat storage is expressed as the snow temperature change, and the temperature is estimated from the residuals $Q_{n e t}$ of energy input into the snow layer and the sensible and latent heat fluxes given in Eq. (9). Snow starts melting when the snow temperature reaches $0^{\circ} \mathrm{C}$. When there is an increase in energy $Q_{n e t}$ in the snow with $S_{W E}$ during a time $\Delta t$, the change in snow temperature $\Delta T_{S}$ can be calculated using the specific heat of ice $c_{i}$ :

$$
\Delta T_{S}=\frac{Q_{n e t}}{\rho_{w} S_{W E} c_{i}} \Delta t .
$$

\section{c. Snow melting and freezing}

Figure 3 shows the computational flowchart for calculations of snow melting and freezing. We set two conditions: the snow temperature $T_{S}$ does not exceed $0^{\circ} \mathrm{C}$ and the liquid water retention is zero when the temperature is below $0^{\circ} \mathrm{C}$. When the snow temperature is $0^{\circ} \mathrm{C}$, melting occurs by the energy input to the snow, $Q_{\text {net }}>0$ (Fig. 3a). When the energy is released from the snow and there is water retention in the 
(a) Snow temperature of $0^{\circ} \mathrm{C}$

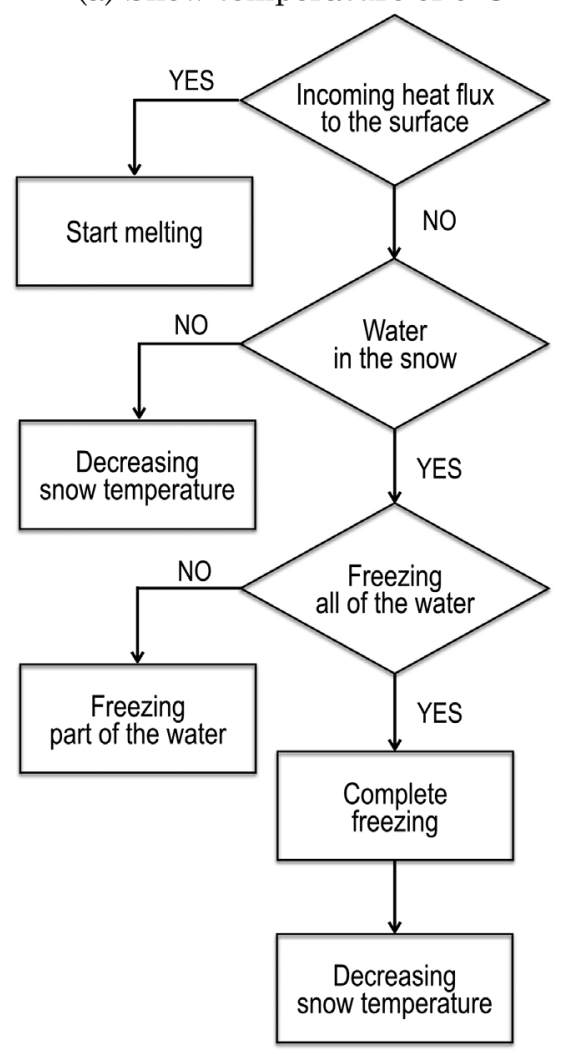

(b) Snow temperature below $0^{\circ} \mathrm{C}$

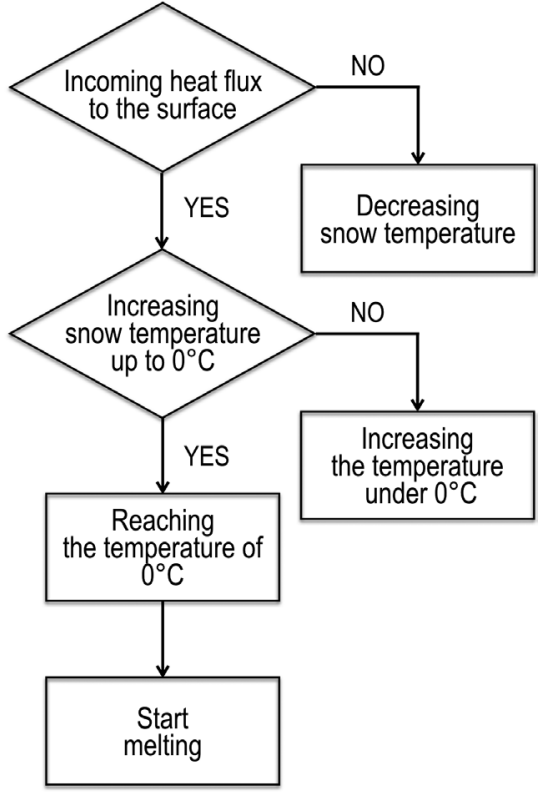

Fig. 3. Computational flowchart illustrating snow temperature, melting and freezing in the snow layer.

snow, the water freezes until it is all frozen. The snow temperature increases with the energy input to the snow at temperatures below $0^{\circ} \mathrm{C}$. When the temperature reaches $0^{\circ} \mathrm{C}$, the snow starts melting (Fig. 3b). The amount of snow melt $M$ in $\Delta t$ is

$$
M=\min \left(S_{W E}, \frac{S_{W E} c_{i}}{L_{F}} \times \max \left(0, \Delta T_{S}-\left(T_{0}-T_{S}\right)\right)\right)
$$

where $T_{0}$ is $0^{\circ} \mathrm{C}$. When the temperature is below $0^{\circ} \mathrm{C}$, the change in snow temperature $\Delta T_{S}$ can also be expressed as in Eq. (12).

\section{d. Snow coverage}

The diagnostic approach estimates the fractions of snow coverage $f_{S}$ on the roof and the ground separately (see Appendix B.2), whereas the prognostic approach expresses them in one equation:

$$
f_{S}=\min \left(\frac{S_{W E}}{S_{W E}^{\max }}, 1\right) .
$$

\section{Methods of model evaluation}

To evaluate the performance of the snowpack scheme itself and its behavior in the coupled model, NHRCM, we conducted offline and online experiments using the enhanced SPUC model, as well as the original SPUC model and a simple biosphere model (SiB). The simulated snow was compared with observational data for verification.

\subsection{Comparison of the four models}

The first two models considered were the two versions of the enhanced SPUC that used the new urban snowpack schemes (hereafter sSPUC): The enhanced SPUC with the diagnostic approach will be referred to as sSPUCdgn and that with the prognostic approach as sSPUCprg. The third model was the original version of the SPUC (no snow), which treats the snow as liquid precipitation with the same temperature as that of the lowest atmospheric layer in the model. The fourth model did not include the SPUC, and this was the improved MRI/JMA SiB (iSiB; Hirai and 
Oh'izumi 2004), which we used to simulate the snow process.

The iSiB model represents snow accumulation in three layers (Table 1). The five main physics processes used in the model are as follows: the density of fresh snow affected by wind and air temperatures (Kajikawa 1989), densification with consideration of compactive viscosity (Kojima 1967; Shinojima 1967; Yamazaki et al. 1991), heat conduction with a thermal conductivity dependent on snow bulk density (Strum et al. 1997), linear aging of the snow albedo (Aoki et al. 2003), and the bulk method for sensible and latent heat fluxes (Beljaars and Holtslag 1991). The maximum snow water content was a constant.

The snowpack schemes were applied to the modeling of the snowpack on the ground around a building and the building roof in the SPUC, but the snowpack on the building walls was not considered. When we used the schemes in the SPUC coupled with the NHRCM, equations for sensible and latent heat fluxes between the entire urban canopy and the atmosphere above it were modified by considering the heat exchanges between the urban canopy and the atmosphere above it and among the building roof, building walls, and ground around the building and the canopy. We also estimated radiation exchanges between the urban surfaces, including snow-covered surfaces, considering multiple reflections by using the radiosity method (Aoyagi and Takahashi 2012).

\subsection{Experimental design}

The SPUC model can be set only as a uniform pattern for urban geometry in an urban grid. Buildings with a height of $10 \mathrm{~m}$ were arranged regularly and accounted for $60 \%$ of all building lots. The residuals of the building lots, and the other areas except the building lots, were the ground areas in the urban grid. This setup for the urban geometry was used for the simulated temperature in megacities and small cities in Japan (Aoyagi et al. 2012). We did not take any anthropogenic heat into account. The importance of anthropogenic heat in cold areas during winter has been pointed out by Mori and Sato (2015), but we were unable to obtain an appropriate dataset for all of the simulated cities. This is one of the limitations of our experiments with respect to the reproduction of snow depth and the other parameters.

\section{a. Offline experiments}

sSPUC can be driven by meteorological forcing. We carried out an offline simulation of sSPUC forced by the observed data at the Institute of Low Temperature
Science (ILTS; $141.35^{\circ} \mathrm{E}, 43.08^{\circ} \mathrm{N}$ ), Hokkaido University, for the two winters of 2006/07 and 2007/08. We selected the ILTS because not only snow depth but also the other values relative to snow processes are observed there. The meteorological forcing comprises seven elements: surface air temperature at $1.5 \mathrm{~m}$, wind velocity at $1.5 \mathrm{~m}$, relative humidity at $1.5 \mathrm{~m}$, surface pressure, precipitation, and downward shortwave and longwave radiation. The integral time step was $120 \mathrm{~s}$. We analyzed the simulated snow processes over an urban grid that was assumed to be Sapporo. The parameters tuned for the offline experiments are shown in Appendix C.

\section{b. Online experiments}

We performed the downscaling simulations from the Japanese 55-year reanalysis data (JRA-55; Kobayashi et al. 2015; Harada et al. 2016) with two nested domains as online experiments. The outer domain had a horizontal resolution of $20 \mathrm{~km}$, while the inner domain has a horizontal resolution of $5 \mathrm{~km}$. Figure 4 shows the location of these two domains, and the experimental parameters are given in Table 2. Because of the computational cost, we set two inner domains: domain 2 covered the main island of Japan and included snowy sites with deep-to-shallow snow depths, and domain $2^{\prime}$ covered Hokkaido, including the site used in the offline experiment above. We describe mainly the simulated results from domain 2 in Section 4.2.

The JRA-55 dataset has a horizontal resolution of $1.25^{\circ}$ at six-hourly intervals and was used to provide the initial and boundary conditions for the outer domain. The model in the outer domain was integrated from 20th July of the first year to 1st June of the following year, including a spin-up period covering the initial 40 days. Integration of the model in the inner domain started four days after the start date for the outer domain. A one-way nesting technique was used for each domain. We analyzed the data from five winters (October to May) between 2006 and 2011, simulated by the NHRCM with a $5-\mathrm{km}$ grid interval.

The same model parameterizations for physical processes were applied to the 20- and 5-km NHRCM domains except for the SPUC model. A bulk scheme with an ice phase and predicted mixing ratios of cloud water, rain, cloud ice, snow, and graupel were used for the cloud microphysics processes (Ikawa et al. 1991). We also used the Kain-Fritsch convective parameterization scheme (Kain and Fritsch 1993). The Yabu et al. (2005) scheme was used for clear sky radiation, and the Kitagawa (2000) scheme for cloud radiation. 

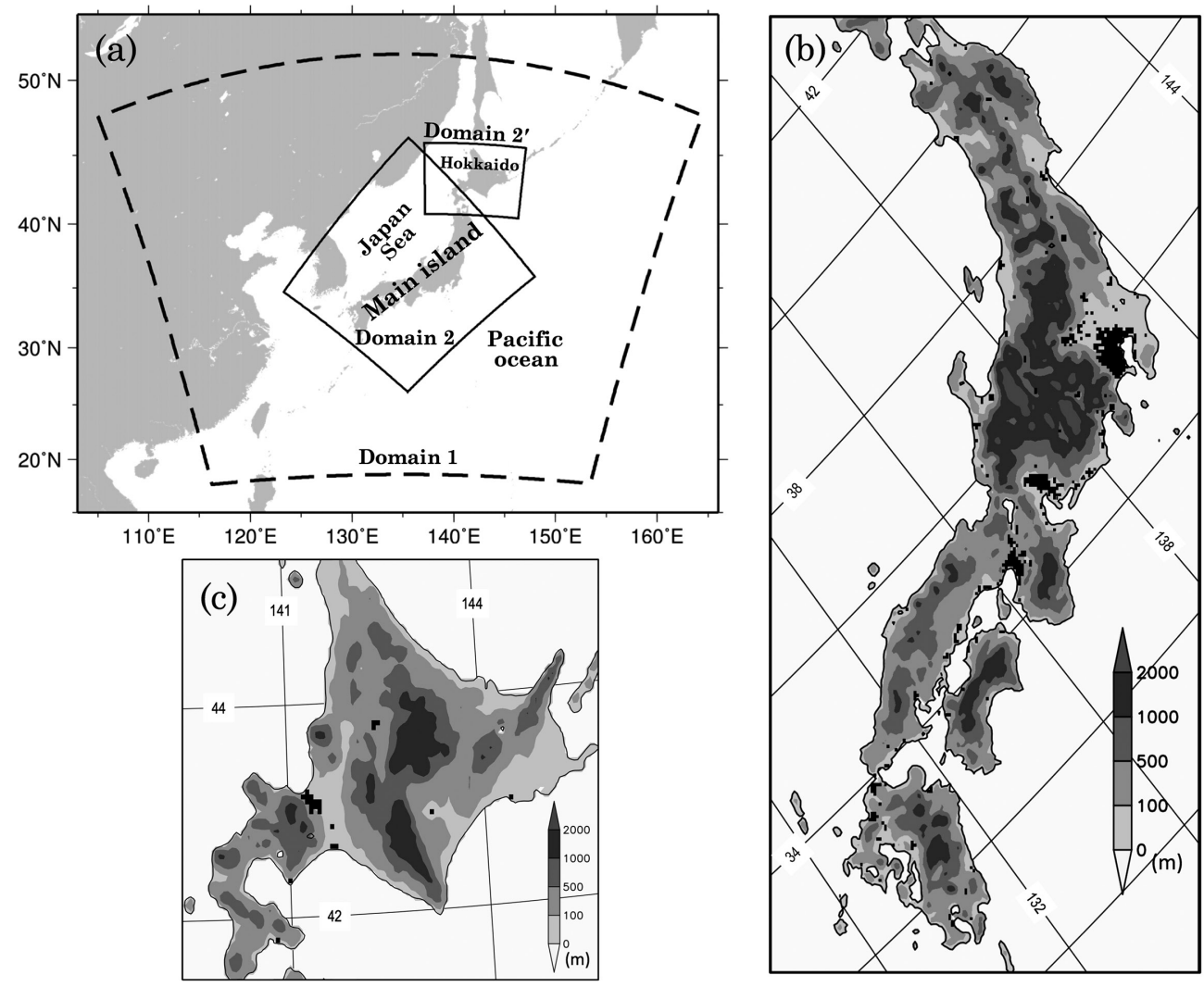

Fig. 4. (a) Computational domain and (b) topography (shading) and urban areas (black) around the main island of Japan in the analyzed area removing the lateral buffer area from computational domain 2. (c) The same as (b) but for domain $2^{\prime}$. Outer dashed square in (a) indicates a domain with a 20-km horizontal resolution and inner squares indicate those with a $5-\mathrm{km}$ resolution.

Table 2. Setup for each computational domain.

\begin{tabular}{|c|c|c|c|}
\hline & Domain 1 & Domain 2 & Domain $2^{\prime}$ \\
\hline Horizontal resolution & $20 \mathrm{~km}$ & \multicolumn{2}{|c|}{$5 \mathrm{~km}$} \\
\hline Number of horizontal grids & $211 \times 175$ & $301 \times 321$ & $151 \times 111$ \\
\hline Number of vertical layers & 40 & \multicolumn{2}{|c|}{50} \\
\hline Model top & $22055 \mathrm{~m}$ & \multicolumn{2}{|c|}{$21801 \mathrm{~m}$} \\
\hline Thickness of bottom/top layer & $20 \mathrm{~m} / 1180 \mathrm{~m}$ & \multicolumn{2}{|c|}{$20 \mathrm{~m} / 904 \mathrm{~m}$} \\
\hline Time step & $40 \mathrm{~s}$ & \multicolumn{2}{|c|}{$20 \mathrm{~s}$} \\
\hline
\end{tabular}

The improved Mellor-Yamada level 3 (Nakanishi and Niino 2004) was used as a boundary layer scheme, and the $\mathrm{SiB}$ model as a land surface scheme.

The SPUC model was applied only to urban grids in the $5-\mathrm{km}$ NHRCM. The land surface parameters were derived according to Aoyagi et al. (2012). The land-use dataset was the National Land Numerical Information provided by the Ministry of Land, Infrastructure, Transport and Tourism of Japan for
2009. We defined the urban grid as a model grid that occupies $50 \%$ or more by urban-related land use. The urban surface in the iSiB is a slab surface without any surface geometry and with either bare soil or broadleaf shrubs with soil as the land use. The parameters in the snowpack scheme were retuned for the online experiments, by considering the maximum snow depths and snow durations in the Japanese cities represented in our model (Appendix C). 


\subsection{Observational data}

The model performance was evaluated using observations of snow at the sites operated by the ILTS and by the JMA. However, it is difficult to obtain observational data from the roofs and ground areas around the buildings in Japanese urban canopies. Snow at the ILTS site can be regarded as that on the urban canopy ground because of its location. Furthermore, the snow temperatures and snow density that are observed there were also available. Thus, we compared outcomes from the offline simulations with those at the ILTS from 2006 to 2008. Snow depth on the roof was estimated from the snow on the ground as in Nakamura et al. (1984). The snow accumulation on the roof was taken to be $60 \%$ of that on the ground until the accumulation peaks, and then, the depths decreased while maintaining the difference in depth at the peak between the roof and ground. The probable range of the depth on the roof was estimated from the observed depths on the ground at the JMA's regional headquarters in Sapporo and the Shiraishi civil engineering center $\left(141.43^{\circ} \mathrm{E}, 43.04^{\circ} \mathrm{N}\right)$, as well as from the depth on the roof of an apartment house in the Shiraishi area of Sapporo (http://cacaomameh.web.fc2.com/). The snow water equivalent is the sum of the product of the snow-layer thickness and the snow density in each layer.

We also used daily data from the JMA-manned sta- tions and the Automated Meteorological Data Acquisition System (AMeDAS) sites for the five winters from 2006 to 2011 to uniformly assess the representation of snow on the ground over Japan. We focused mainly on evaluating the snow depth at the 48 sites shown in Fig. 5 (circles). The observed depth at each site was compared with the simulated depth in the grid square that included the site. The observed snowfall amount was estimated from the precipitation amount and the ratio of the density of liquid water $\left(1 \mathrm{~g} \mathrm{~cm}^{-3}\right)$ to that of fresh snow $\left(0.1 \mathrm{~g} \mathrm{~cm}^{-3}\right)$. According to operational use at the JMA, the hourly snowfall depth is calculated as the difference in the snow depth with respect to that at the previous hour when the snow depth increases, and the total of the hourly depths during a 24 -h period is defined as the daily snowfall depth.

\subsection{Surface air temperature in models}

The surface air temperature that we compared with the observed temperature was the air temperature at $1.5 \mathrm{~m}(\mathrm{~T} 1.5 \mathrm{~m})$ from the NHRCM, but the iSiB model and SPUC models calculate the temperature using different diagnostic equations. The iSiB model yields a vertical profile from the ground surface temperature to air temperature at $20 \mathrm{~m}(\mathrm{~T} 20 \mathrm{~m})$, and $\mathrm{T} 1.5 \mathrm{~m}$ is then diagnosed from the profile. Meanwhile, in the SPUC model, the air temperature in the urban canopy is $\mathrm{T} 1.5 \mathrm{~m}$, which is a function of $\mathrm{T} 20 \mathrm{~m}$ and the tempera-

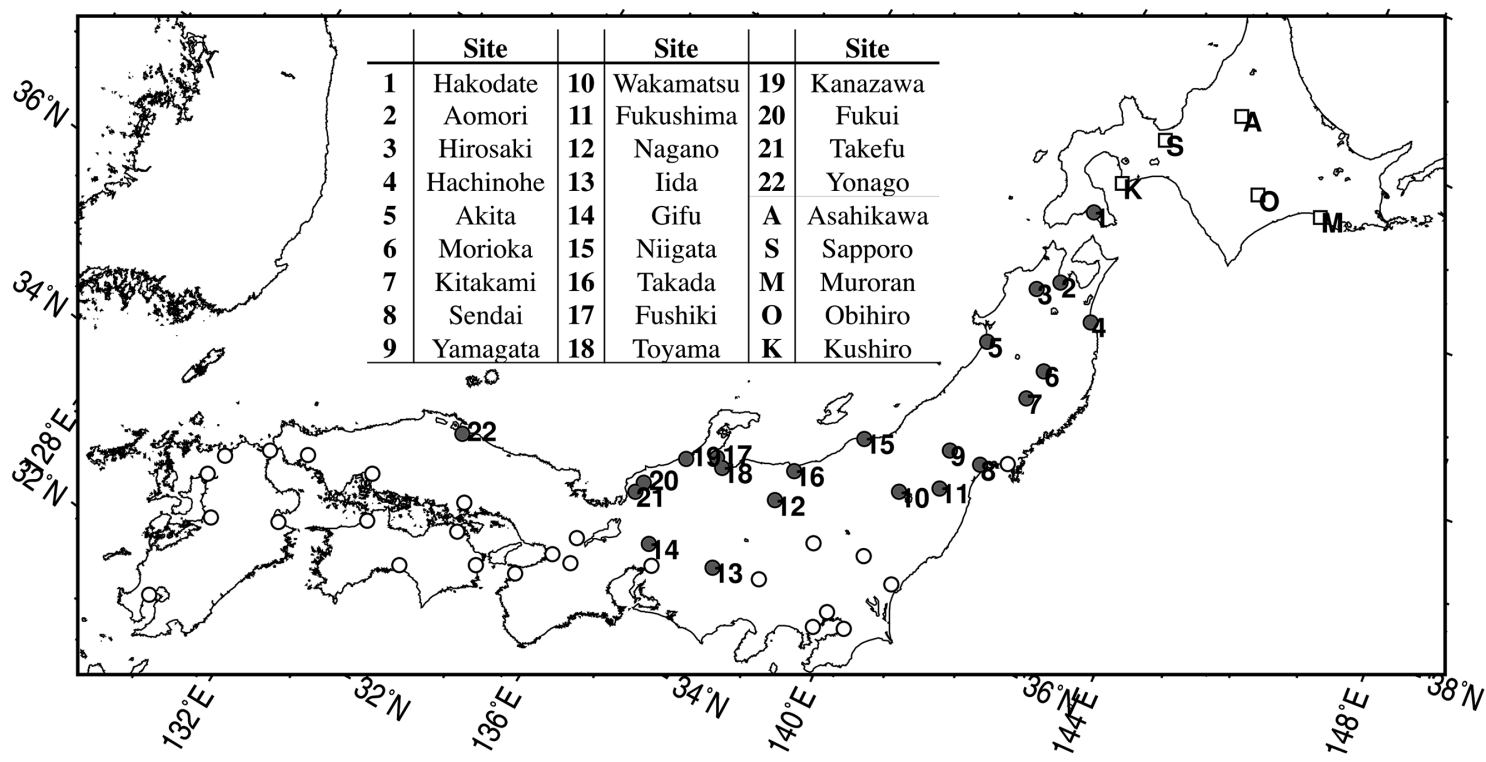

Fig. 5. Geographical distribution of observation sites for the evaluation. Circled sites are simulated in domain 2 , and square sites in domain $2^{\prime}$. Gray closed circles indicate sites with an annual maximum snow depth of at least $5 \mathrm{~cm}$. 
tures at the building roof and walls, and the ground around the building. The temperatures in the urban canopy interact with each other.

\section{Experimental results}

\subsection{Comparison of the simulations in an urban canopy}

Figure 6 shows the simulated snow depths on the ground around a building and on the building roof for the two winters of 2006/07 and 2007/08. In both years, the simulated seasonal maximum depths and the other peaks on the roof are similar to the estimated values from the observations. Although the maximum depths on the ground are underestimated, the peaks occur at the same time as those seen in the observation, as well as on the roof. The difference in the seasonal variations over the accumulating period is small between the two schemes, and both show similar variation to those seen in the observations. On the other hand, during the melting period, the melting progresses more quickly in sSPUCprg on the ground in both winters and on the roof in 2006/07. Thus, the durations of snow cover on both the ground and the roof are shorter than those in sSPUCdgn, and about 10 days shorter than the observations in $2006 / 07$. It is clear that both schemes can recreate the differences observed in the snow depths found on the ground and roof. That is to say, both schemes give smaller snow depths on the roof than on the ground. We attribute this to the larger net radiation on the roof and differences in the heat capacity and internal temperature. On a real roof, the surrounding wind influences snow accumulation, but the current versions of the sSPUC do not include these wind-driven accumulation or redistribution processes, which may bring about a bias in snow depth.

Seasonal variations in the snow water equivalent $S_{W E}$, the snow temperature $T_{S}$, and snow density $\rho_{S}$ are shown in Fig. 7. Regarding the variations in $S_{W E}$ on the ground in 2006/07, sSPUCprg performs well despite both schemes showing the same bias in the snow depth during the accumulation period from December to the middle of February (Fig. 6a). In addition, the peak is closer to the observations in sSPUCprg. During the melting period from the middle of February to March, sSPUCdgn is similar to the observations, whereas the variations are underestimated by sSPUCprg, as with the variations in the snow depth (Fig. 6a). The difference in the performance between the two schemes is small in 2007/08. In summary, for
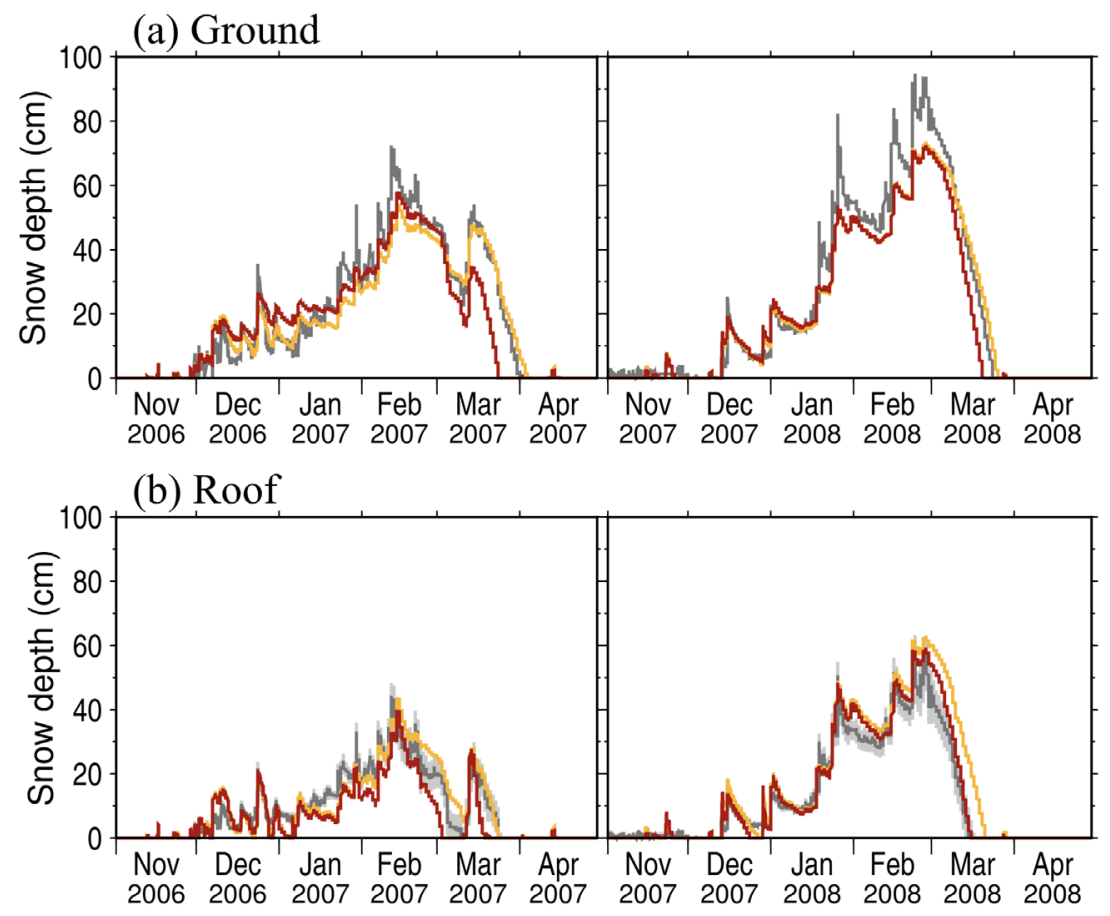

Fig. 6. Snow depths (a) on the ground around a building and (b) on the roof during the two winters of 2006/07 and 2007/08. Gray, yellow and red lines represent the observations, and the simulations using sSPUCdgn and sSPUCprg, respectively. Light gray shading over the observed depth on the roof is the probable range. 
the snow temperature and snow density, it is difficult to say which scheme is better. However, sSPUCprg better estimates the temperature variations seen in the observations in 2007/08 than does sSPUCdgn.

As illustrated in Fig. 8, sSPUCdgn and sSPUCprg give distinctly different simulated sensible and latent heat fluxes on the snow surface, especially during the melting period (mid-February to March). The average latent heat flux from March 1 to March 15 during the melting period is positive (indicating evaporation) in both schemes. However, the sensible heat flux is positive, i.e., heat release from the snow surface, in sSPUCdgn but negative, i.e., heat conducted toward the snow surface, in sSPUCprg (Table 3). During the same period, because the snow temperature is lower than the air temperature in both schemes, a negative sensible heat flux will appear as SSPUCprg indicates. This feature is common for the surface energy balance in a snowmelt season, namely, a downward sensible heat flux and upward latent heat flux (e.g., Takeuchi et al. 1993; Cline 1997). The reason for the inconsistency in sSPUCdgn is that the sensible heat flux is estimated as the residual of the energy balance; that is to say, the sum of the model errors is added to the flux. In general, because the surface air temperature is higher than the snow surface temperature during the snowmelt period, the sensible heat flux is negative, the latent heat flux is positive, and thus, the energy $\tilde{Q}$ locates between them. However, the latent and sensible heat fluxes, which are defined as a function of $\tilde{Q}$ (Eqs. 6, 7), positively increase because $\tilde{Q}$ overestimates and increases with the increase in $Q^{*}$. The underlying cause of the overestimate is a negative increase in $\Delta Q s$, which is calculated from $Q^{*}$ using empirical factors.

sSPUCprg also generated melting at a reasonable timing. Figure 9 presents the seasonal variations in the melting amount with the snow temperature. Generally, snow melting starts when the snow temperature reaches $0^{\circ} \mathrm{C}$. We show the time of melting $(M>0)$ with the gray line when the snow temperature is less than $0^{\circ} \mathrm{C}$ $\left(T_{S}<0\right)$ over the period of full snow cover. It is clear that melting occurs in sSPUCdgn even when $T_{S}<0$, but that is never seen in sSPUCprg. According to Eq. (8), the melting amount is calculated from the canopy air temperature $\left(T_{a}\right)$ in sSPUCdgn and the snow temperature is not included as an explanatory variable. Furthermore, multiple empirical factors are used for the estimate. As a consequence, sSPUCdgn generates an unrealistic process in the snow layer. From the (a) sSPUCdgn
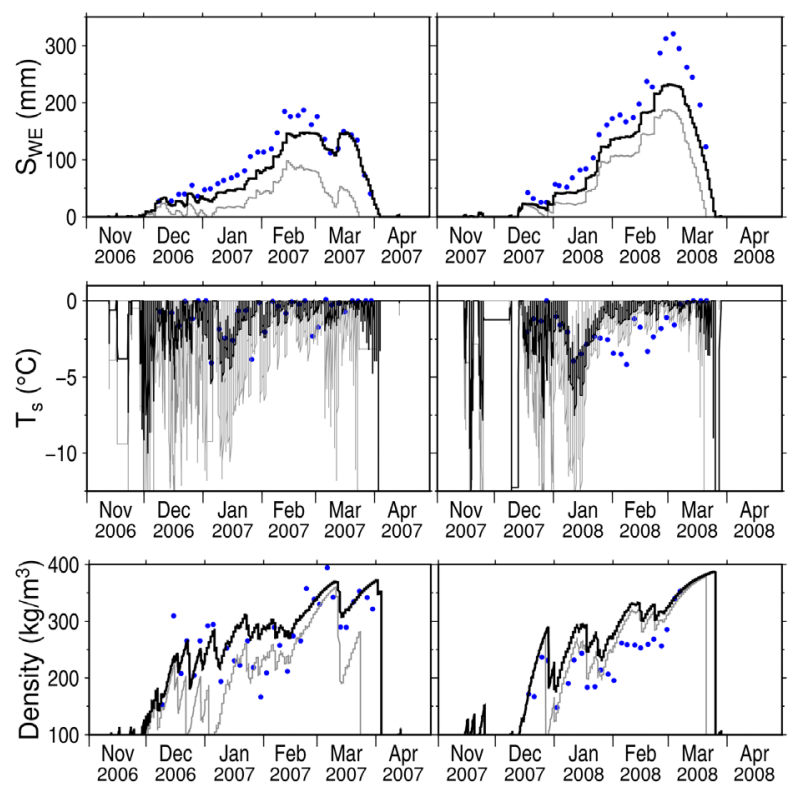

(b) sSPUCprg
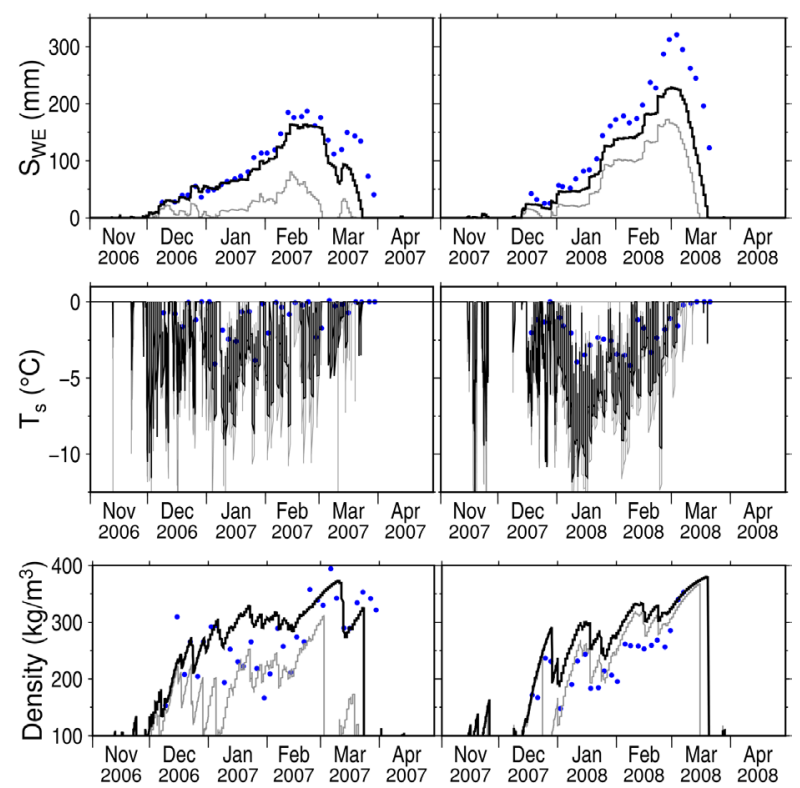

Fig. 7. Snow water equivalent (top), snow temperature (middle), and snow density (bottom) in 2006/07 and 2007/08 are simulated using (a) sSPUCdgn and (b) sSPUCprg. Black and gray lines indicate the seasonal variations on the ground and on the roof, respectively. Blue dots indicate the observed value at the Institute of Low Temperature Science (ILTS), Hokkaido University. 
(a) sSPUCdgn

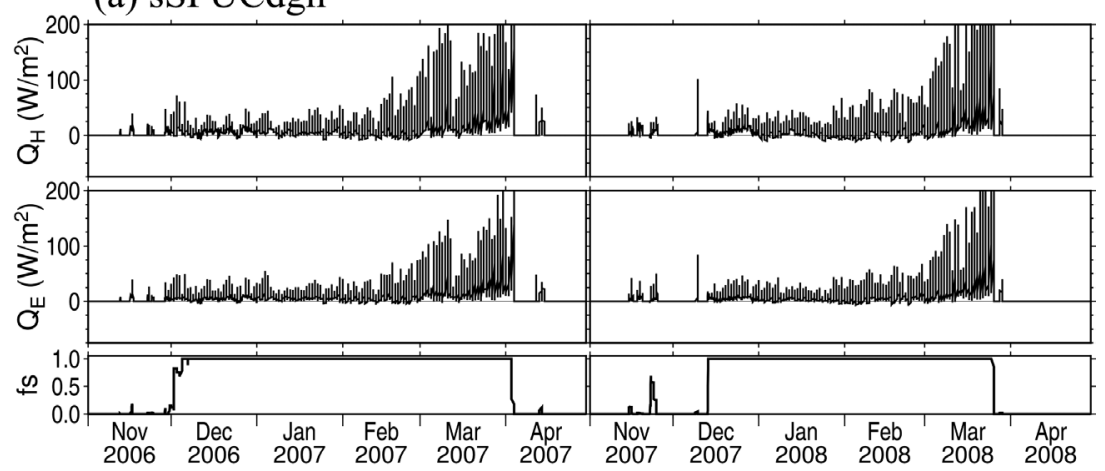

(b) sSPUCprg

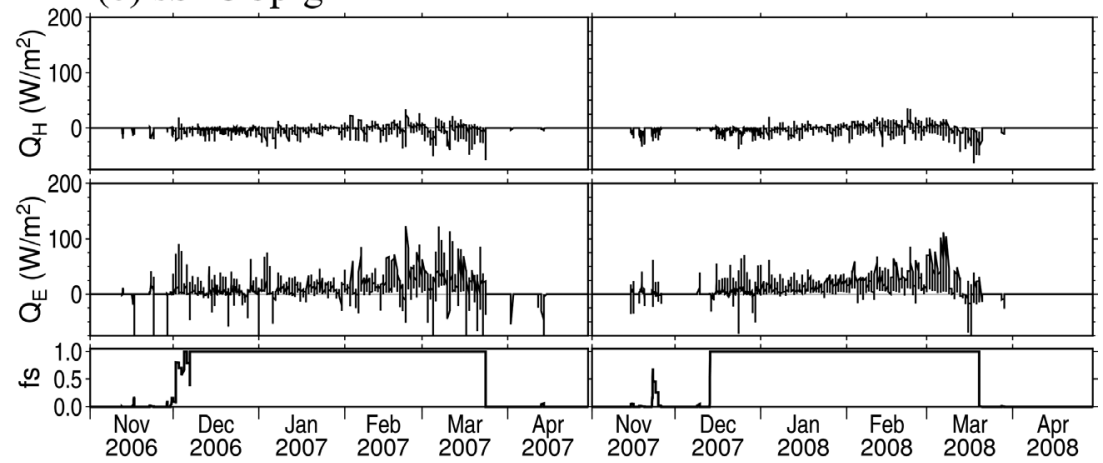

Fig. 8. Sensible heat (top) and latent heat (middle) on the snowy ground around a building and fraction of snow coverage (bottom) over the two winters of 2006/07 and 2007/08 simulated using (a) sSPUCdgn and (b) sSPUCprg. When the fraction is equal to 1 , the grid is entirely covered by snow.

Table 3. Heat fluxes and temperatures averaged over the melting period (March 1-15) for the two winters of 2006/07 and $2007 / 08$.

\begin{tabular}{ccccccc}
\hline & & $Q_{H}$ & $Q_{E}$ & $T_{S}$ & $\begin{array}{c}\text { Forcing for } \\
\text { surface air } \\
\text { temperature }\end{array}$ \\
\cline { 3 - 6 } & & $\mathrm{W} \mathrm{m}^{-2}$ & $\mathrm{~W} \mathrm{~m}^{-2}$ & ${ }^{\circ} \mathrm{C}$ & ${ }^{\circ} \mathrm{C}$ \\
\hline $2006 / 07$ & sSPUCdgn & 34 & 25 & -0.57 & -0.42 \\
& sSPUCprg & -4 & 21 & -0.56 & \\
$2007 / 08$ & sSPUCdgn & 34 & 26 & -0.56 & 0.96 \\
& sSPUCprg & -3 & 17 & -0.10 & \\
\hline
\end{tabular}

sensible heat flux and melting, we find that sSPUCprg can reproduce processes in a snow layer that are more consistent with the physical principles.

\subsection{Climatological properties}

We assessed the model's behavior using online experimental results for climatological properties averaged over the period 2006-2011, at multiple sites over Japan. The seasonal variations evaluated below are the variations averaged over the five winters, and the annual maximum snow depth is the maximum depth of the variation. The snow was on the ground in the $\mathrm{iSiB}$ run and on the ground around a building in the sSPUC runs.

\section{a. Annual maximum snow depth}

To evaluate the performance of each scheme with respect to the annual maximum snow depth at urban sites, the statistics for the depth observed and simulated at the 48 urban sites (circles in Fig. 5) are given in Table 4. The root-mean-square error (RMSE) is defined as

$$
R M S E=\sqrt{\frac{1}{n} \sum_{k=1}^{n}\left(A_{k}-A_{o}\right)^{2}} .
$$

Here, $n$ is the number of sites, $A_{k}$ is the simulated depth, and $A_{o}$ is the observed depth. Although the 
(a) sSPUCdgn

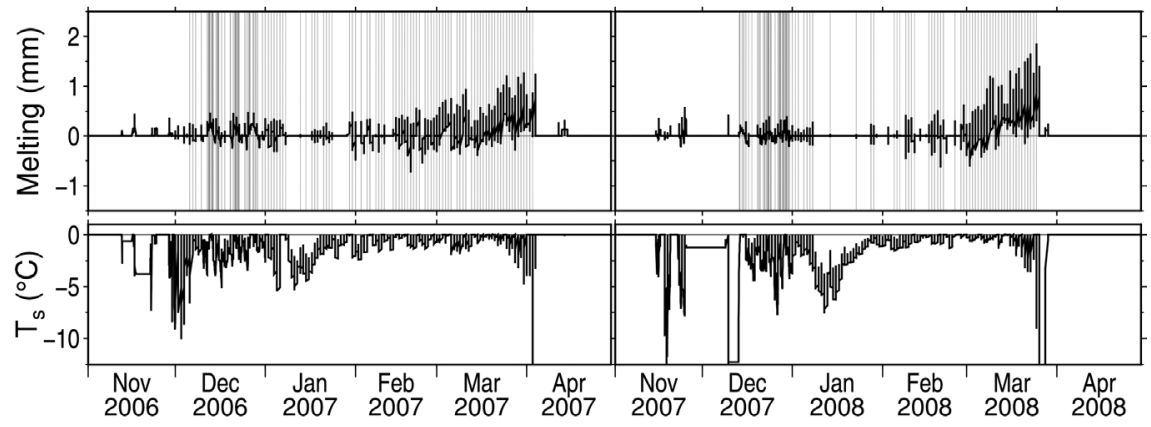

(b) sSPUCprg

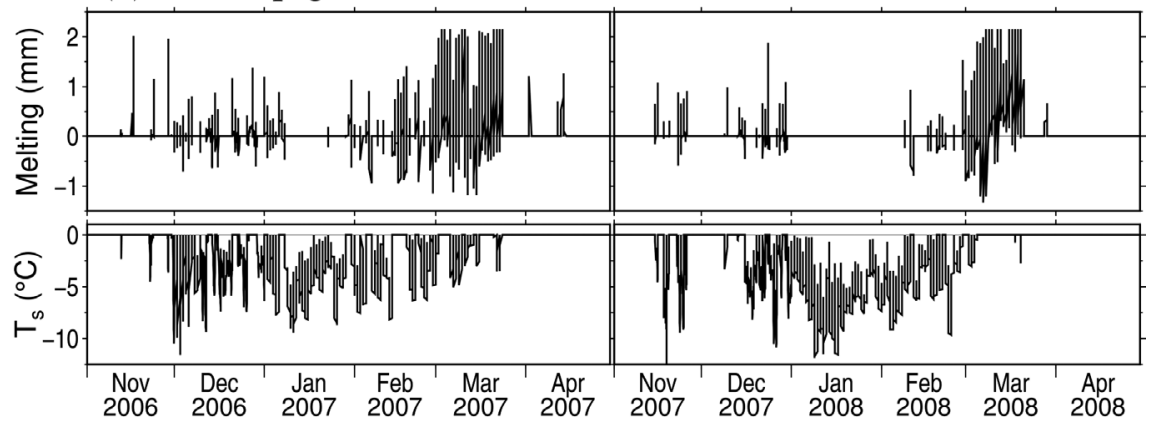

Fig. 9. Melting amount (top) and snow temperature (bottom) on the ground around a building simulated using (a) sSPUCdgn and (b) sSPUCprg. Gray bar on the panel for melting indicates the time of occurrence for melting when the snow temperature is less than $0^{\circ} \mathrm{C}$.

Table 4. Model performance for annual maximum snow depths at the 48 urban sites.

\begin{tabular}{lccccc}
\hline & & Obs. & iSiB & sSPUCdgn & sSPUCprg \\
\hline Mean & $\mathrm{cm}$ & 12 & 13 & 9 & 10 \\
Max./Min. & & $71 / 0$ & $62 / 0$ & $52 / 0$ & $51 / 0$ \\
Averaged bias & $\mathrm{cm}$ & - & 7 & 5 & 5 \\
Negative max./Positive max. & & & $-36 / 28$ & $-47 / 17$ & $-48 / 18$ \\
RMSE & $\mathrm{cm}$ & - & 11 & 10 & 10 \\
Spatial correlation & & - & 0.79 & 0.80 & 0.82 \\
\hline
\end{tabular}

spatial correlation coefficient is slightly larger for sSPUCprg than iSiB, the RMSE and the correlation are almost same among the three schemes. In addition, the differences in the mean depth at the 48 sites and the averaged bias are also small among them. However, comparing the maximum depth in the maximum annual depths at each site, iSiB estimates the closest depth to the observations. SSPUC estimated a maximum of approximately $20 \mathrm{~cm}$ less than the observations. The positive maximum bias was 10 $\mathrm{cm}$ less in sSPUC than iSiB, whereas the negative maximum bias was $10 \mathrm{~cm}$ larger. Therefore, we found that the spatial pattern and statistics averaged over the evaluation sites are similar among the schemes, whereas the maximum and minimum depths at the sites estimated by SSPUC were smaller than those in iSiB. It is difficult to make a distinction between the statistics generated by sSPUCdgn and sSPUCprg.

Next, to assess the accuracy of representation by the snowpack schemes at each site, we will focus on the sites with sufficient snow depth. Thus, we selected 22 sites where the annual maximum snow depth was 

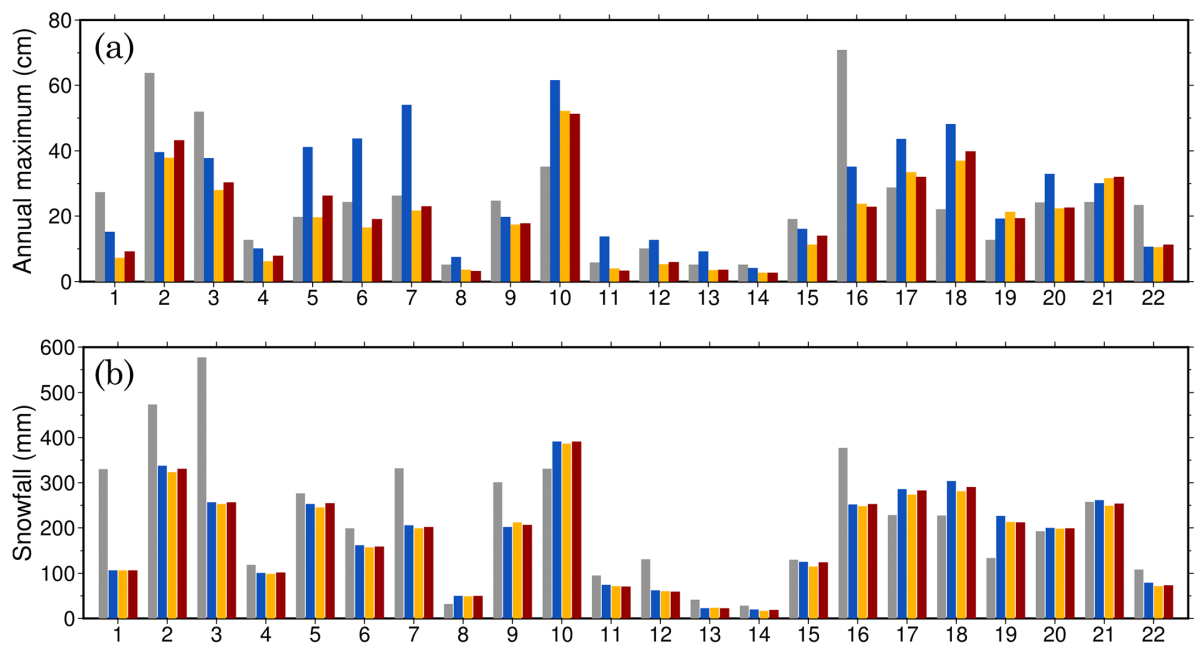

Fig. 10. (a) Annual maximum snow depth and (b) accumulation of snowfall over the winter at the 22 evaluated sites. The colored bars represent the observations (gray) and the simulations using iSiB (blue), sSPUCdgn (yellow), and sSPUCprg (red). Site number on the x-axis corresponds to the number in Fig. 5.

at least $5 \mathrm{~cm}$ (gray-shaded circles in Fig. 5).

Figure 10 shows the annual maximum snow depths and the accumulated snowfall over the winter for each model. At 15 sites with various snow depths, the snow depths simulated by sSPUCprg are closer to the observations than those simulated by sSPUCdgn (Fig. 10a). For sSPUC, among 18 of the sites (i.e., not sites 5, 8, 20, and 21), we found that for four (sites 10, 17, 18, and 19), the simulated depth was deeper than the observed depth when the simulated snowfall was heavier than the observed snowfall, whereas for the other 14 sites (sites $1-4,6-7,9,11-16$, and 22), the simulated depth was shallower where the simulated snowfall was less. On the other hand, for iSiB, at five of the 18 sites (sites 6, 7, 11, 12, and 13), the simulated depth was deeper than observed, despite the simulated snowfall being less than the observed snowfall. In other words, by application of the urban snowpack schemes, the relationship between the bias in the simulated snowfall and that in the simulated snow depth has been clarified; that is to say, an excess bias of simulated depth appears where an overestimated snowfall occurs, and the opposite is also true.

\section{b. Seasonal variations}

To clarify the effect of the urban snowpack schemes on the accumulation and melting of snow, we now focus on seasonal variations at the same 22 sites where the annual maximum snow depth exceeds $5 \mathrm{~cm}$ (gray-shaded circles in Fig. 5). In what follows, we will use the results from iSiB and sSPUCprg.

Figure 11 shows the RMSE and correlation coefficient for the variations in the snow depth over the period from October to May, as well as the bias in the daily mean of surface air temperature from December to March. To calculate the RMSE, $n$ in Eq. (15) was set to the number of days from October 1 to May 31. The RMSE of the seasonal variation when the urban snowpack scheme is used is significantly less at 10 sites than that for iSiB ( $\bigcirc$ in Fig. 11a). The reduction in RMSE exceeds $80 \%$ at Kitakami (site 7). The correlation between the simulated and observed variations is weak at sites with relatively small annual maximum depths in Fig. 10a, and the correlation coefficients for both schemes are similar except at a few sites (sites 8, 14, and 16 in Fig. 11b). At the 10 improved sites, the bias in the daily mean temperature is more than $1{ }^{\circ} \mathrm{C}$. The cold bias decreases when sSPUCprg is used, and is similar to the bias in the original SPUC. Thus, we found that the bias decreases when using the original SPUC without the urban snowpack schemes when compared to iSiB, and the original SPUC brings about an improvement in the temperature represented in the model.

The difference in RMSE between $\mathrm{iSiB}$ and sSPUCprg is small at the sites that are not marked in Fig. 11a. These sites have a cold bias of less than $1{ }^{\circ} \mathrm{C}$ even in iSiB, except for Hirosaki (site 3) and Wakamatsu (site 10). Therefore, when iSiB can accurately represent the variations, the urban snowpack scheme works 

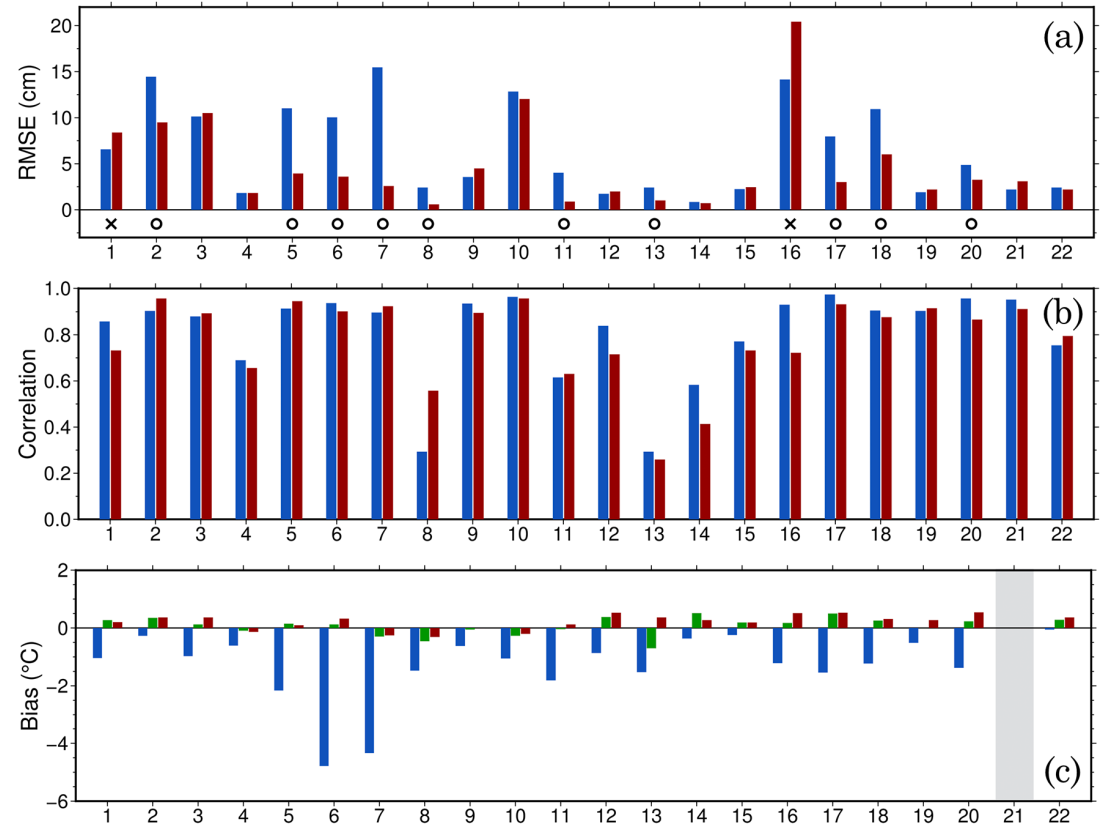

Fig. 11. (a) RMSE for seasonal variations in the snow depth and (b) correlation coefficient between the variations in the observed and simulated depths. Blue and red bars indicate the iSiB and sSPUCprg simulations, respectively. $\bigcirc$ in (a) denotes sites with a significant decrease in RMSE caused by using sSPUCprg, whereas $\times$ denotes sites with increased RMSE. (c) Averaged bias in the daily mean surface air temperature over December to March. Bars are for iSiB (blue), SPUC (green), and sSPUCprg (red). The light gray bar in (c) indicates that the observations are lost. Site number on the x-axis corresponds to the number in Fig. 5.

without any negative influence on the variations.

The seasonal variations in snow depth and daily mean temperature at two of the improved sites are shown in Fig. 12. At Morioka (site 6), the depth difference between iSiB and sSPUCprg increases from the middle of December to March (Fig. 12a). Over this period, the temperature generated by $\mathrm{iSiB}$ is below $0^{\circ} \mathrm{C}$, which is far less than the observations, and in contrast, the temperature simulated by sSPUCprg is higher and close to the observations. The averaged bias of the temperature over the snowpack period decreases from $-4.8^{\circ} \mathrm{C}$ to under $+0.3{ }^{\circ} \mathrm{C}$ when using sSPUC (Fig. 11c). The accumulated snowfall is $20 \%$ less than the observation (Fig. 10b). However, iSiB overestimates the snow depth, and the annual maximum depth is about twice as large as that in the observations. The peak from sSPUCprg is close to the observations except the timing. Kitakami (site 7 ), where the positive bias in the annual maximum depth is the largest among the 22 sites, also has a cold bias of more than $4^{\circ} \mathrm{C}$ in the daily mean temperature simulated by $\mathrm{iSiB}$, and the biases in the depth and temperature are improved using sSPUCprg (Figs. 10a, 11c).

The RMSE was also reduced at Aomori (site 2). However, unlike the other improved sites, the decrease in the cold bias was small (Figs. 11c, 12b). The snowfall was less in the simulations than in the observations (Fig. 10b), and the snow depth was smaller in the simulations (Fig. 12b). Figure $12 \mathrm{~b}$ shows that the difference between iSiB and sSPUCprg becomes large in the middle of January because of the rapid melting simulated by iSiB. The temperature is below $0^{\circ} \mathrm{C}$ at that time, and the snow temperature is about $-3^{\circ} \mathrm{C}$ (not shown). As melting does not occur at the temperatures in sSPUCprg (Fig. 3b), the simulated snow depth remains almost until February. As a consequence, the variation in the snow depth is close to the observations and the RMSE is small in sSPUCprg.

Figure 13 shows the seasonal variation at sites where the RMSE increases when sSPUCprg is used. Takada (site 16) is the site where the negative maximum bias in the annual maximum depth appears in all schemes and remains large even if the land scheme is improved (Fig. 10a). The snowfall is underestimated at Takada (Fig. 10b) and Hakodate (site 1), which also 
(a) Morioka (site 6)

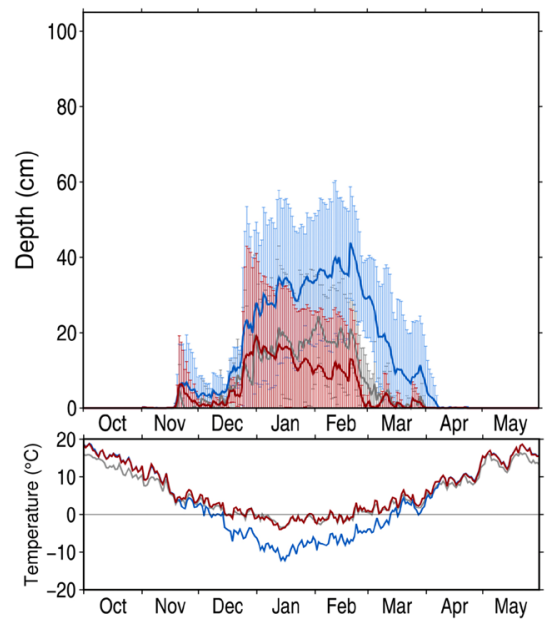

(b) Aomori (site 2)

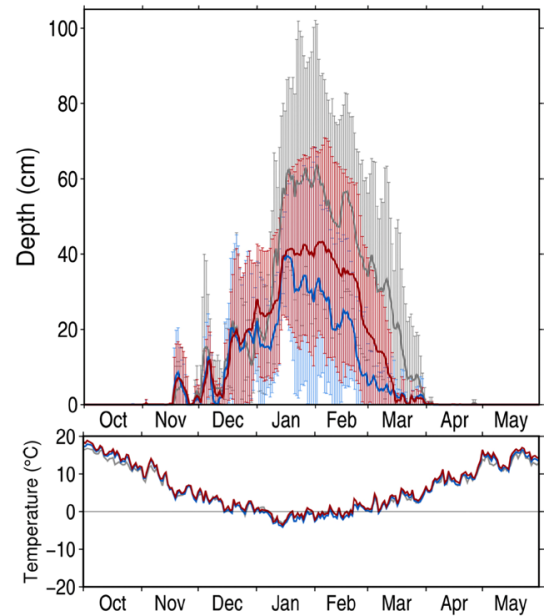

Fig. 12. Seasonal variations in snow depth (top) and daily mean of surface air temperatures (bottom) at (a) Morioka and (b) Aomori. The lines indicate the observations (gray), iSiB (blue), and sSPUCprg (red). Vertical lines in the top panels indicate the variance in snow depth over each winter from 2006 to 2011.

(a) Takada (site 16)

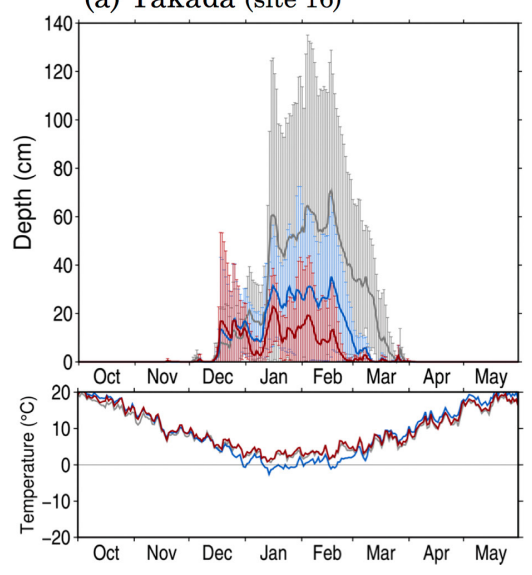

(b) Sapporo (site S)

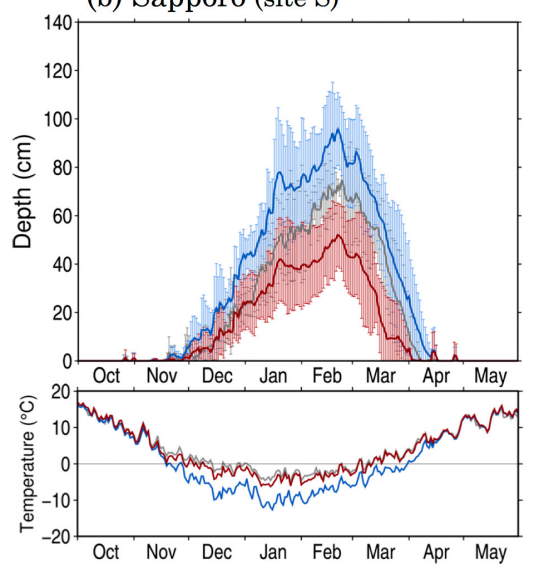

(c) Asahikawa (site A)

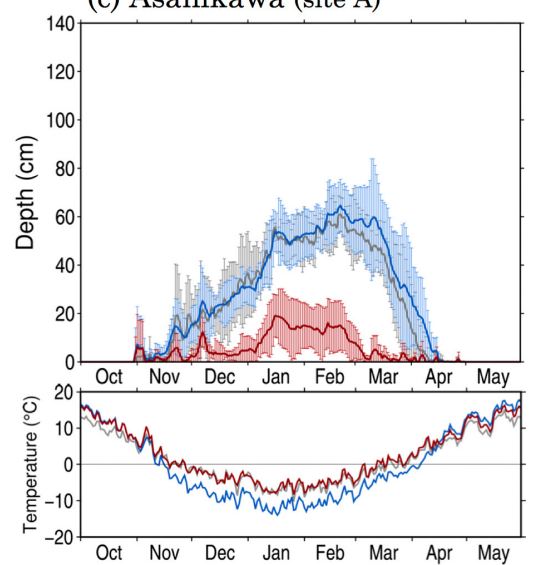

Fig. 13. Same as Fig. 12 but for (a) Takada, (b) Sapporo, and (c) Asahikawa.

shows an increase in the RMSE. Compared to the observations, the lower snowfall leads to an underestimation of the simulated depth. The temperature in the sSPUCprg simulation is above $0^{\circ} \mathrm{C}$ even during the snow-covered period, and such conditions mean that it is difficult for the snow to accumulate (Fig. 13a). In contrast, the temperature in iSiB is lower than that in both sSPUCprg and the observations, and the depth is greater than that generated by sSPUCprg. Thus, iSiB seems to perform better than sSPUCprg. The underestimation of snowfall is also obvious at two of the five urban sites in Hokkaido (squares in Fig. 5): Sapporo (Fig. 13b) and Asahikawa (Fig. 13c). Although snow accumulation at Sapporo is $40 \%$ less and that at Asahikawa is $60 \%$ less over the period 2006-2011 (not shown), the snow depth simulated by $\mathrm{iSiB}$ is closer to the observations than that simulated by sSPUCprg when its cold bias appears in iSiB.

Although the RMSE and temperature bias are small at Nagano (site 12; Figs. 11a, c), the simulated variations in snow depth are poorly correlated with the observations (Fig. 11b). In Fig. 14, the variation 


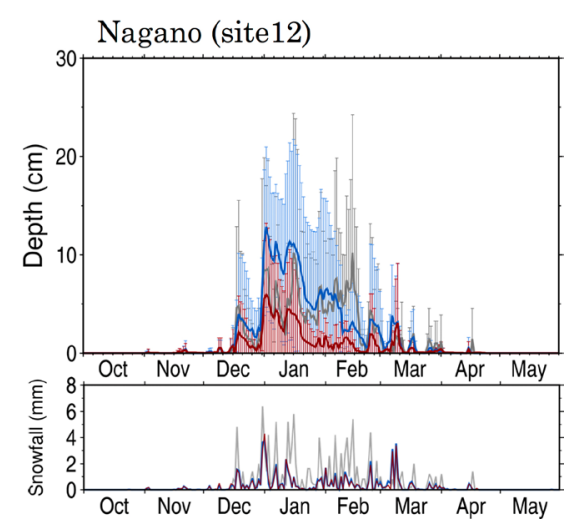

Fig. 14. Seasonal variations in snow depth (top) and snowfall (bottom) at Nagano. The lines indicate the observations (gray), iSiB (blue), and sSPUCprg (red). Vertical lines in the top panels indicate the variance in snow depth over each winter from 2006 to 2011.

in snowfall shows that, compared to the observations, the snowfall is less in February, and some peaks in snowfall from the end of December to the middle of January are unclear. Therefore, poor accuracy of the simulated snowfall leads to a low correlation between the variations in the observed and simulated depths. A similar feature can be seen at Iida (site 13), which shows the smallest correlation coefficient, and Gifu (site 14).

The RMSEs are still large despite the use of the urban snowpack scheme at Aomori (site 2), Hirosaki (site 3), and Wakamatsu (site 10; Fig. 11a). Compared to the observed annual maximum snow depth, the simulated depth is large at Wakamatsu, with an overestimated snowfall, but small at the other two sites with an underestimated snowfall (Figs. 10a, b). Moreover, these sites show a strong correlation between the observed and simulated seasonal variations (Fig. 11b).
Figure 15 shows the rank correlation coefficients for the seasonal variations between snowfall and snow depth. At 17 of the 22 sites, the coefficients for sSPUCprg are closer to those for the observations than those for iSiB. Also, the coefficient is larger in sSPUCprg than in $\mathrm{SiB}$ at 12 of the sites. We found that the relationship between the variations in snow accumulation and melting and in snowfall amount given by sSPUCprg resemble the observed relationship rather than that generated by iSiB. In other words, the introduction of the snowpack scheme brings about increased dependence of the snow accumulation and melting on snowfall in the NHRCM. Therefore, the accuracy of snowfall becomes more important for the simulation of snow accumulation and melting processes when using the urban snowpack scheme.

\section{Discussion}

A rapid decrease in the snow depth on the ground appears in March 2007 in the sSPUCprg simulation (Fig. 6). This depth is computed from $S_{W E}$ and the snow density. The density represents the observed values well, but $S_{W E}$ was underestimated over the study period (Fig. 7b). While $S_{W E}$ was underestimated, especially in the middle of March, the simulated snow temperature reached $0^{\circ} \mathrm{C}$. This simulated snow temperature could be higher than the actual values during this period, and thus, the melting progresses more rapidly than in reality. However, verifying this interpretation was difficult because of the lack of actual measurements.

We will now consider how we can improve the cold bias of more than $1^{\circ} \mathrm{C}$ associated with the daily mean temperature generated by $\mathrm{iSiB}$. We first compared $\mathrm{T} 20 \mathrm{~m}$ and the ground temperature between $\mathrm{iSiB}$ and sSPUCprg, the point at which the cold bias appears, because the temperatures are used to estimate $T 1.5 \mathrm{~m}$ as described in Section 3.4. Figure 16 shows these temperatures at Morioka where the cold bias is more

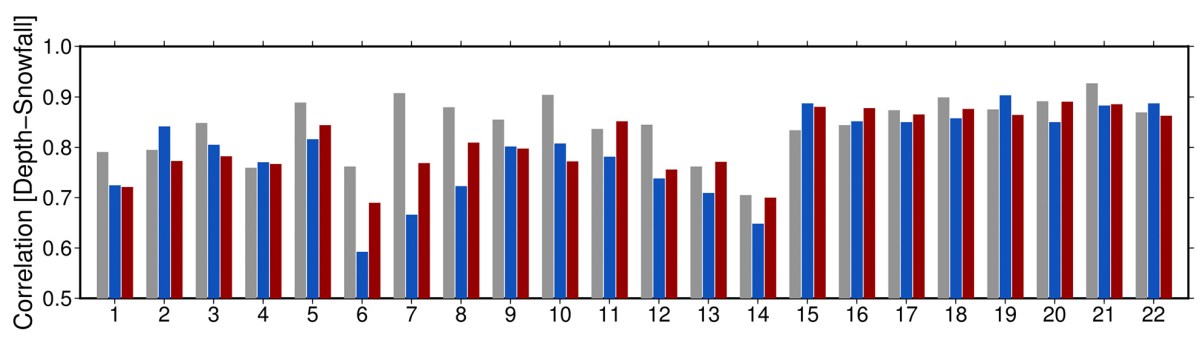

Fig. 15. Rank correlations between snowfall and snow depth in the observations (gray) and in the simulations performed using iSiB (blue) and sSPUCprg (red) at the 22 evaluated sites. Site number on the $x$-axis corresponds to the number in Fig. 5. 
than $1{ }^{\circ} \mathrm{C}$ (Fig. 12a). The difference in $\mathrm{T} 20 \mathrm{~m}$ between iSiB and sSPUCprg is small over the snowpack period from December to March, while that of the snow surface temperature is large. The greatest difference in the surface temperature is $7.8^{\circ} \mathrm{C}$, which strongly suggests that the large cold bias of $\mathrm{T} 1.5 \mathrm{~m}$ in iSiB comes from the snow surface temperature being too low.

In sSPUCprg, the temperatures on the snowy roof and walls affect the ground surface temperatures. The roof temperature is similar to the ground temperature, whereas the wall temperature is above $0^{\circ} \mathrm{C}$ over this period (Fig. 17). This is because snow does not cover the wall in the scheme, and thus, the wall is heated during the daytime. The heated wall is a heat source, and the sensible heat flux and longwave radiation released from the wall help prevent a decrease in the air temperature of the urban canopy and snowy ground temperature. Simulated results for a large sensible heat flux in a snowy urban canopy during the daytime have also been provided by Mori and Sato (2015). According to their results, because of the high albedo of snowy road surfaces, the absorption of daytime net shortwave radiation by walls increases and a larger sensible heat flux from the walls is apparent in snowy urban areas than in snow-free urban areas during the
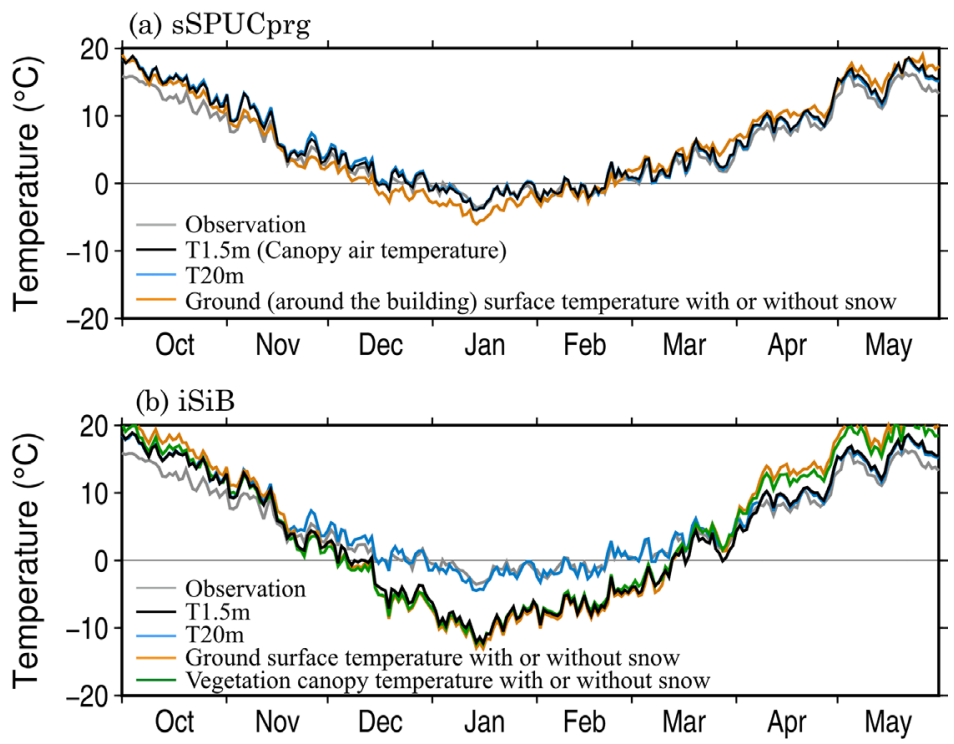

Fig. 16. Seasonal variation in the daily mean temperature at Morioka from simulations performed using (a) sSPUCprg and (b) iSiB. Lines indicate the observations (gray), the surface air temperature at $1.5 \mathrm{~m}$ (black), the air temperature at the model level of $20 \mathrm{~m}$ above the ground surface (light blue), and the ground surface temperature with or without snow (orange). The green line in (b) indicates the temperature in the vegetation canopy with or without snow.

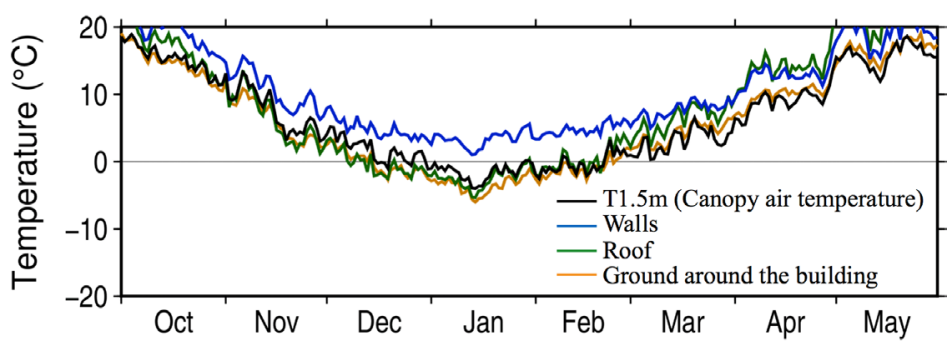

Fig. 17. Seasonal variation in the daily mean temperature in the urban canopy at Morioka. Lines indicate the surface air temperature at $1.5 \mathrm{~m}$ (black), the temperatures at the walls (blue), the roof with or without snow (green), and the ground around a building with or without snow (orange). 
day. Similar behavior was simulated in our experiments.

On the other hand, in iSiB simulation, the contribution to the snow surface temperature change that differs from the sSPUC models is the vegetation canopy. Once snow covers the canopy, the canopy temperature decreases rapidly to the snow surface temperature due to the low heat capacity of the vegetation canopy (not shown). Although this low heat capacity brings about an increase in the canopy temperature via insolation, the canopy temperature quickly returns to a low value without it. A snowcovered vegetation canopy releases much less longwave radiation than the building walls, and the small input of radiation to the ground causes a greater decrease in the snow surface temperature in the iSiB simulation. Besides, the deep snow depth and flat snow surface in iSiB generate a large albedo, and thus, the input of shortwave radiation is less than that simulated by sSPUCprg. This decrease in radiation causes a low snow surface temperature, and hence, the low surface air temperature, and leads to the difficulty of snow melt in iSiB.

We also found some inaccuracies in the snow surface temperatures generated by iSiB. The snow surface temperature was considerably lower than $\mathrm{T} 20 \mathrm{~m}$ and lower than the temperature in the snow layer closest to the snow surface (not shown). As a consequence, we have insisted that there is a serious issue, but not any bugs, with the prognostic equation that controls the snow surface temperature.

There were some sites with a small cold bias over the snowpack period even in the $\mathrm{iSiB}$ simulation. Kawase et al. (2018) indicated that the cold bias tends to appear in the northeastern region of the main island during winter as a characteristic of simulations by NHRCM with the same 5-km grid spacing. However, from our simulations, the cold bias is relatively small in the Niigata region. The locations where the bias appears remain unknown.

\section{Conclusions}

Snowpack schemes were introduced into the SPUC model to represent seasonal change in urban snow cover. We verified that the schemes were able to replicate snow processes including accumulation, melting, and freezing. From the perspective of the associated computational costs and the realism of the physical processes, we tested two schemes: one based on a diagnostic approach and the other on a prognostic approach. The prognostic approach was developed by modifying the diagnostic approach for the melting and freezing energy and the sensible and latent heat fluxes.

Our offline experiments indicated that both new snowpack schemes, sSPUCdgn and sSPUCprg, simulate seasonal maximum depths on the roof that are similar to the values estimated from the observations and that the timing of the peak depths on the roof and ground matched the observations. Regarding the seasonal variation in depth, although the low precision of the snow water equivalent renders the duration of snow covering shorter in sSPUCprg, the pattern of variations is almost the same in the two schemes and similar to that in the observations over the accumulating period. On the other hand, sSPUCprg reproduced a more reasonable estimation of the sensible and latent heat fluxes and the timing of melting because it does not include empirical factors for snow processes, which differs from sSPUCdgn. Therefore, we propose that both schemes are useful for the reproduction of seasonal variations in snow cover and its peak, but sSPUCprg is needed when we wish to consider the processes in the snow layer.

sSPUC also showed an improvement in the simulated annual maximum snow depth in the online experiments, and the bias of the depth decreased compared to iSiB. For the 22 cities with a snow depth of at least $5 \mathrm{~cm}$, sSPUCprg reproduced the snow depths more accurately at more than half of the sites.

The RMSE of the seasonal variation decreases significantly using sSPUCprg at sites with a cold bias above $1{ }^{\circ} \mathrm{C}$ in iSiB. The cold bias arises from a lower input of radiation to the snow surface, and hence, an underestimation of the snow surface temperature. These conditions in the $\mathrm{iSiB}$ simulation mean that the snow is more difficult to melt. In the urban snowpack scheme, building walls are heated during the daytime because they are not considered to have snow cover. In addition, the calculation method for snow surface temperature is different from iSiB. Thus, the heated wall and improved estimation of the snow surface temperature suppress the cold bias, leading to a better representation of the snow depth in sSPUCprg.

The relationship between snowfall and snow depth moves closer to that seen in the observations when using the urban snowpack scheme. Therefore, the introduction of the snowpack scheme brings about increased dependence of the urban snow on snowfall, and it will be necessary to improve simulations of snowfall to reproduce the urban snow cover more accurately.

We were able to reproduce the urban snowpack and its seasonal variations using our schemes developed in this study, and there is now a clear pathway toward 
more precise modeling of snow processes in urban areas. Consequently, we can expect that the precision of future projections of urban climates in snowy areas will also be improved.

\section{Acknowledgment}

This paper was supported by the Social Implementation program on Climate change Adaptation Technology (SI-CAT), MEXT, Japan. The snowpack scheme development and the offline experiments were conducted under the SOUSEI and TOUGOU programs, MEXT. For the online experiments, we used the disaster prevention information systems of the National Research Institute for Earth Science and Disaster Resilience (NIED). The authors would like to thank Prof. Takeshi Yamazaki in Tohoku University and Dr. Shiori Sugimoto in the Japan Agency for Marine-Earth Science and Technology for their valuable comments for this study and Dr. Noriko N. Ishizaki and Ms. Misa Koyano in the NIED for supporting the data collection. The authors also acknowledge the insightful comments of the editor and two anonymous reviewers on an earlier version of this manuscript.
Appendix A: Notation

\begin{tabular}{|c|c|c|}
\hline & unit & \\
\hline$a_{1}$ & - & Site-dependent parameters in the OHM \\
\hline$a_{2}$ & s & Site-dependent parameters in the OHM \\
\hline$a_{f}$ & $\mathrm{~m}^{\circ} \mathrm{C}^{-1}$ & Factor for freezing \\
\hline$a_{r} \quad 1$ & $\mathrm{~m}\left(\mathrm{~W} \mathrm{~m}^{-2}\right)^{-1}$ & Factor for radiation melt \\
\hline$a_{t}$ & $\mathrm{~m}^{\circ} \mathrm{C}^{-1}$ & Factor for temperature melt \\
\hline$c_{i}$ & $\mathrm{~J} \mathrm{~kg}^{-1}{ }^{\circ} \mathrm{C}^{-1}$ & Specific heat of ice \\
\hline$c_{p}$ & $\mathrm{~J} \mathrm{~kg}^{-1} \mathrm{~K}^{-1}$ & Specific heat of air \\
\hline$c_{q}$ & $\mathrm{~Pa}$ & Bulk coefficient for specific humidity flux \\
\hline$C_{h}$ & - & Bulk coefficient for sensible heat flux \\
\hline$C_{q}$ & - & Bulk coefficient for latent heat flux \\
\hline$d_{S}$ & $\mathrm{~m}$ & Snow depth \\
\hline$E$ & $\mathrm{~m} \mathrm{~s}^{-1}$ & Evaporation rate \\
\hline$f_{S}$ & - & Fraction of snow coverage \\
\hline$K_{E}$ & - & $\begin{array}{l}\text { Tuning parameter for the bulk } \\
\text { coefficient, } C_{q}\end{array}$ \\
\hline$K_{H}$ & - & $\begin{array}{l}\text { Tuning parameter for the bulk } \\
\text { coefficient, } C_{h}\end{array}$ \\
\hline$K_{S}$ & $\mathrm{~W} \mathrm{~m}^{-1} \mathrm{~K}^{-1}$ & Thermal diffusivity for snow \\
\hline$L_{F}$ & $\mathrm{~J} \mathrm{~kg}^{-1}$ & Latent heat of fusion \\
\hline$M$ & $\mathrm{~m}$ & Snow melting and freezing amount \\
\hline$P_{R}$ & $\mathrm{~m} \mathrm{~s}^{-1}$ & Liquid precipitation rate \\
\hline$P_{S}$ & $\mathrm{~m} \mathrm{~s}^{-1}$ & Solid precipitation rate \\
\hline$q_{a}$ & - & Specific humidity \\
\hline$q_{\text {sat }}$ & - & Saturated specific humidity \\
\hline$Q^{*}$ & $\mathrm{~W} \mathrm{~m}^{-2}$ & Net radiation \\
\hline$\tilde{Q}$ & $\mathrm{~W} \mathrm{~m}^{-2}$ & Total of sensible heat and latent heat \\
\hline$Q_{E}$ & $\mathrm{~W} \mathrm{~m}^{-2}$ & Latent heat \\
\hline$Q_{G}$ & $\mathrm{~W} \mathrm{~m}^{-2}$ & Conductive heat \\
\hline$Q_{H}$ & $\mathrm{~W} \mathrm{~m}^{-2}$ & Sensible heat \\
\hline$Q_{M}$ & $\mathrm{~W} \mathrm{~m}^{-2}$ & Snowmelt latent heat \\
\hline$Q_{n e t}$ & $\mathrm{~W} \mathrm{~m}^{-2}$ & $\begin{array}{l}\text { Total of stored or used energy in the } \\
\text { snow layer }\end{array}$ \\
\hline$Q_{P}$ & $\mathrm{~W} \mathrm{~m}^{-2}$ & Heat released from liquid precipitation \\
\hline$\Delta Q_{S}$ & $\mathrm{~W} \mathrm{~m}^{-2}$ & Heat storage change \\
\hline$R$ & $\mathrm{~m} \mathrm{~s}^{-1}$ & $\begin{array}{l}\text { Outflow of liquid precipitation and } \\
\text { snow melting }\end{array}$ \\
\hline$s$ & $\mathrm{~Pa}{ }^{\circ} \mathrm{C}^{-1}$ & Gradient of saturation specific humidity \\
\hline$S_{W E}$ & $\mathrm{~m}$ & Snow water equivalent \\
\hline$S_{W E}^{\max }$ & $\mathrm{m}$ & Maximum equivalent \\
\hline$t$ & $\mathrm{~s}$ & Time \\
\hline$T_{0}$ & ${ }^{\circ} \mathrm{C}$ & $0^{\circ} \mathrm{C}$ \\
\hline$T_{a}$ & ${ }^{\circ} \mathrm{C}$ & Canopy air temperature \\
\hline$T_{G}$ & $\mathrm{~K}$ & Internal temperature of soil or roof \\
\hline$T_{S}$ & $\mathrm{~K}$ & Snow temperature \\
\hline$U_{a}$ & $\mathrm{~m} \mathrm{~s}^{-1}$ & Wind velocity in the canopy \\
\hline$\beta$ & - & Evaporation efficiency \\
\hline$\gamma$ & $\mathrm{Pa}{ }^{\circ} \mathrm{C}^{-1}$ & Psychrometric constant \\
\hline$\rho$ & $\mathrm{kg} \mathrm{m}^{-3}$ & Air density \\
\hline$\rho_{w}$ & $\mathrm{~kg} \mathrm{~m}^{-3}$ & Water density \\
\hline
\end{tabular}




\section{Appendix B: Snowpack scheme based on Järvi et al. (2014)}

The snowpack scheme that used a diagnostic estimation was based on the scheme developed by Järvi et al. (2014). The scheme diagnoses freezing and melting snow using the net radiation and surface air temperature.

\section{B.1 Albedo and density of snow}

The albedo at the surface of the snow layer and the density in the layer vary with time. The snow albedo $\alpha_{s}$ in the scheme decreases linearly during the period of snow accumulation and exponentially during that of snow melt. The time variation is estimated by

$$
\begin{aligned}
& \alpha_{s}(t+\Delta t) \\
& = \begin{cases}\max \left(\alpha_{s}(t)-\frac{\Delta t}{\tau_{d} / \tau_{a}}, \alpha_{s}^{\min }\right) & T_{a} \leq 0 \\
{\left[\alpha_{s}(t)-\alpha_{s}^{\min }\right] \exp \left(-\frac{\Delta t}{\tau_{d} / \tau_{f}}\right)+\alpha_{s}^{\min }} & T_{a}>0,\end{cases}
\end{aligned}
$$

where $T_{a}$ is the canopy air temperature $\left({ }^{\circ} \mathrm{C}\right), t$ is time, $\Delta t$ is a time step, $\tau_{d}$ is $86400 \mathrm{~s}$ (one day), $\tau_{a}$ and $\tau_{f}$ are time constants for albedo damping ( 0.018 and 0.11 , respectively), and $\alpha_{s}^{\min }$ is the minimum snow albedo with a value of 0.18 . Negative $T_{a}$ corresponds to the period of accumulation and positive snowmelt. The time constant $\tau_{a}$ is chosen such that the albedo reaches its minimum approximately 37 days after the snow is fresh, and $\tau_{f}$ such that the e-folding time is approximately 9 days. Snowfall of over $2 \mathrm{~mm} \mathrm{~h}^{-1}$ resets the albedo to that for fresh snow, $\alpha_{s}^{\max }=0.85$.

The time variation of snow density $\rho_{s}\left(\mathrm{~kg} \mathrm{~m}^{-3}\right)$ in the snow layer is calculated from

$$
\rho_{s}(t+\Delta t)=\left[\rho_{s}(t)-\rho_{s}^{\max }\right] \exp \left(-\frac{\tau_{r}}{\tau_{h}} \Delta t\right)+\rho_{s}^{\max },
$$

where $\rho_{s}^{\max }$ is the maximum snow density, $\tau_{r}$ is a time constant, and $\tau_{h}$ is $3600 \mathrm{~s}(1 \mathrm{~h})$. The maximum density is set to $400 \mathrm{~kg} \mathrm{~m}^{-3}$, and the density of fresh snow is assumed to be $100 \mathrm{~kg} \mathrm{~m}^{-3}$. When snowfall starts, the density is calculated using those of fresh snow and the snow at the time in the proportion of the snow water equivalents.

Fresh snow can retain more water than old snow. As densification progresses, the snow can hold less water and the liquid water retention decreases. The liquid water retention capacity $C^{R}(\mathrm{~mm})$ is expressed as

$$
C^{R}= \begin{cases}C_{\min }^{R} & \rho_{s} \geq \rho_{e} \\ C_{\min }^{R}+\left(C_{\max }^{R}-C_{\min }^{R}\right) \frac{\rho_{s}-\rho_{e}}{\rho_{s}} & \rho_{s}<\rho_{e} .\end{cases}
$$

Here, $C_{\max }^{R}$ and $C_{\min }^{R}$ are the maximum and minimum capacities, respectively. The threshold density $\rho_{e}$ is set to $200 \mathrm{~kg} \mathrm{~m}^{-3}$.

The heat released from liquid precipitation $Q_{P}$ $\left(\mathrm{W} \mathrm{m}^{-2}\right.$ ) with a temperature above $0^{\circ} \mathrm{C}$ is calculated from

$$
Q_{P}=\rho_{w} c_{w} P T_{a},
$$

where $c_{w}$ is the specific heat of water $\left(\mathrm{J} \mathrm{kg}^{-1} \mathrm{~K}^{-1}\right), \rho_{w}$ is water density, and $P$ is precipitation $\left(\mathrm{m} \mathrm{s}^{-1}\right)$.

\section{B.2 Snow depth and snow coverage}

The snow depth $d_{s}(\mathrm{~m})$ is calculated using the snow water equivalent $S_{W E}$ :

$$
d_{s}=S_{W E} \frac{\rho_{w}}{\rho_{s}}
$$

The fractions of snow coverage $f_{S}$ on a building roof and on the ground around the building are calculated separately:

$$
\begin{aligned}
& f_{S, \text { roof }}= \begin{cases}0.5 \frac{S_{W E}}{S_{W E, \text { roof }}^{\max }} & \frac{S_{W E}}{S_{W E, \text { roof }}^{\max }}<0.9 \\
\min \left(\left[\frac{S_{W E}}{S_{W E, \text { roof }}^{\max }}\right]^{8}, 1\right) & \frac{S_{W E}}{S_{W E, \text { roof }}^{\max }} \geq 0.9,\end{cases} \\
& f_{S, \text { ground }}=\min \left(\left[\frac{S_{W E}}{S_{W E, \text { ground }}^{\max }}\right]^{2}, 1\right) .
\end{aligned}
$$


Appendix C: Tuned parameters

\begin{tabular}{|c|c|c|c|c|}
\hline & \multicolumn{2}{|c|}{ Offline experiment } & \multicolumn{2}{|c|}{ Online experiment } \\
\hline & sSPUCdgn & sSPUCprg & sSPUCdgn & sSPUCprg \\
\hline$\tau_{r}$ & \multicolumn{2}{|c|}{0.003} & \multicolumn{2}{|c|}{0.003} \\
\hline$S_{W E, \text { groud }}^{\max }$ & \multicolumn{2}{|c|}{10.0} & \multicolumn{2}{|c|}{10.0} \\
\hline$S_{W E, \text { roof }}^{\max }$ & \multicolumn{2}{|c|}{10.0} & \multicolumn{2}{|c|}{10.0} \\
\hline$a_{1}$ & 0.25 & - & 0.25 & - \\
\hline$a_{2}$ & 0.6 & - & 0.6 & - \\
\hline$a_{f}$ & $1.5 \times 10^{-5}$ & - & $1.5 \times 10^{-5}$ & - \\
\hline$a_{r}$ & $0.5 \times 10^{-6}$ & - & $0.5 \times 10^{-6}$ & - \\
\hline$a_{t}$ & $1.5 \times 10^{-5}$ & - & $1.5 \times 10^{-5}$ & - \\
\hline$K_{E}$ & - & 0.5 & - & 5.0 \\
\hline$K_{H}$ & - & 0.125 & - & 0.125 \\
\hline
\end{tabular}

\section{References}

Adachi, S. A., F. Kimura, H. Kusaka, M. G. Duda, Y. Yamagata, H. Seya, K. Nakamichi, and T. Aoyagi, 2014: Moderation of summertime heat island phenomena via modification of the urban form in the Tokyo metropolitan area. J. Appl. Meteor. Climatol., 53, 18861900.

Aoki, T., A. Hachikubo, and M. Hori, 2003: Effects of snow physical parameters on shortwave broadband albedos. J. Geophys. Res., 108, 4616, doi:10.1029/2003JD 003506.

Aoyagi, T., and N. Seino, 2011: A square prism urban canopy scheme for the NHM and its evaluation on summer conditions in the Tokyo metropolitan area, Japan. J. Appl. Meteor. Climatol., 50, 1476-1496.

Aoyagi, T., and S. Takahashi, 2012: Development of an urban multilayer radiation scheme and its application to the urban surface warming potential. Bound.-Layer Meteor., 142, 305-328.

Aoyagi, T., N. Kayaba, and N. Seino, 2012: Numerical simulation of the surface air temperature change caused by increases of urban area, anthropogenic heat, and building aspect ratio in the Kanto-Koshin area. $J$. Meteor. Soc. Japan, 90B, 11-31.

Argüeso, D., J. P. Evans, L. Fita, and K. J. Bormann, 2014: Temperature response to future urbanization and climate change. Climate Dyn., 42, 2183-2199.

Beljaars, A. C. M., and A. A. M. Holtslag, 1991: Flux parameterization over land surfaces for atmospheric models. J. Appl. Meteor., 30, 327-341.

Bengtsson, L., and G. Westerström, 1992: Urban snowmelt and runoff in northern Sweden. Hydrol. Sci. J., 37, 263-275.

Chen, F., and J. Dudhia, 2001: Coupling an advanced land surface-hydrology model with the Penn State-NCAR MM5 modeling system. Part I: Model implementation and sensitivity. Mon. Wea. Rev., 129, 569-585.

Cline, D. W., 1997: Snow surface energy exchanges and snowmelt at a continental, midlatitude Alpine site. Water Resour. Res., 33, 689-701.

Deardorff, J. W., 1978: Efficient prediction of ground surface temperature and moisture, with inclusion of a layer of vegetation. J. Geophys. Res., 83, 1889-1903.

Dupont, S., T. L. Otte, and J. K. S. Ching, 2004: Simulation of meteorological fields within and above urban and rural canopies with a mesoscale model (MM5). Bound.-Layer Meteor, 113, 111-158.

Grimmond, C. S. B., H. A. Cleugh, and T. R. Oke, 1991: An objective urban heat storage model and its comparison with other schemes. Atmos. Environ., 25B, 311-326.

Hamdi, R., H. Van de Vyver, R. De Troch, and P. Termonia, 2014: Assessment of three dynamical urban climate downscaling methods: Brussels's future urban heat island under an A1B emission scenario. Int. J. Climatol., 34, 978-999.

Hamdi, R., O. Giot, R. De Troch, A. Deckmyn, and P. Termonia, 2015: Future climate of Brussels and Paris for the 2050s under the A1B scenario. Urban Climate, 12, 160-182.

Harada, Y., H. Kamahori, C. Kobayashi, H. Endo, S. Kobayashi, Y. Ota, H. Onoda, K. Onogi, K. Miyaoka, and K. Takahashi, 2016: The JRA-55 Reanalysis: Representation of atmospheric circulation and climate variability. J. Meteor. Soc. Japan, 94, 269-302.

Hirai, M., and M. Oh'izumi, 2004: Development of a new land-surface model for JMA-GSM. Extended abstract of 20th Conference on Weather Analysis and Forecasting/16th Conference on Numerical Weather Prediction, P2.22. [Available at https://ams.confex. com/ams/84Annual/webprogram/Paper68652.html.]

Ikawa, M., H. Mizuno, T. Matsuo, M. Murakami, Y. Yamada, and K. Saito, 1991: Numerical modeling of the convective snow cloud over the Sea of JapanPrecipitation mechanism and sensitivity to ice crystal nucleation rates-. J. Meteor. Soc. Japan, 69, 641-667.

Järvi, L., C. S. B. Grimmond, and A. Christen, 2011: The surface urban energy and water balance scheme (SUEWS): Evaluation in Los Angeles and Vancouver. J. Hydrol., 411, 219-237.

Järvi, L., C. S. B. Grimmond, M. Taka, A. Nordbo, H. Setälä, and I. B. Strachan, 2014: Development of the surface urban energy and water balance scheme (SUEWS) for cold climate cities. Geosci. Model Dev., 7, 1691-1711.

Kain, J. S., and J. M. Fritsch, 1993: Convective parameterization for mesoscale models: The Kain-Fritsch scheme. The Representation of Cumulus Convection in Numerical Models. Kerry, A. E., and D. J. Raymond (eds.), Amer. Meteor. Soc., Boston, MA, 165-170.

Kajikawa, M., 1989: Relationship between new snow density and shape of snow crystals. J. Japan. Soc. Snow and Ice, 51, 178-183 (in Japanese with English 
abstract).

Karsisto, P., C. Fortelius, M. Demuzere, C. S. B. Grimmond, K. W. Oleson, R. Kouznetsov, V. Masson, and L. Järvi, 2016: Seasonal surface urban energy balance and wintertime stability simulated using three land-surface models in the high-latitude city Helsinki. Quart. J. Roy. Meteor. Soc., 142, 401-417.

Kawase, H., H. Sasaki, A. Murata, M. Nosaka, and N. N. Ishizaki, 2015: Future changes in winter precipitation around Japan projected by ensemble experiments using NHRCM. J. Meteor. Soc. Japan, 93, 571-580.

Kawase, H., A. Murata, R. Mizuta, H. Sasaki, M. Nosaka, M. Ishii, and I. Takayabu, 2016: Enhancement of heavy daily snowfall in central Japan due to global warming as projected by large ensemble of regional climate simulations. Climatic Change, 139, 265-278.

Kawase, H., T. Sasai, T. Yamazaki, R. Ito, K. Dairaku, S. Sugimoro, H. Sasaki, A. Murata, and M. Nosaka, 2018: Characteristics of synoptic conditions for heavy snowfall in western to northeastern Japan analyzed by the $5-\mathrm{km}$ regional climate ensemble experiments. $J$. Meteor. Soc. Japan, 96, 161-178.

Kitagawa, H., 2000: Radiation processes. Report of Numerical Prediction Division (Suuchiyohouka Houkoku Bessatsu Houkoku), 46, 16-31 (in Japanese).

Kobayashi, S., Y. Ota, Y. Harada, A. Ebita, M. Moriya, H. Onoda, K. Onogi, H. Kamahori, C. Kobayashi, H. Endo, K. Miyaoka, and K. Takahashi, 2015: The JRA-55 Reanalysis: General specifications and basic characteristics. J. Meteor. Soc. Japan, 93, 5-48.

Kojima, K., 1967: Densification of seasonal snow cover. Phys. Snow Ice, 1, 929-952.

Kondo, H., Y. Genchi, Y. Kikegawa, Y. Ohashi, H. Yoshikado, and H. Komiyama, 2005: Development of a multi-layer urban canopy model for the analysis of energy consumption in a big city: Structure of the urban canopy model and its basic performance. Bound.-Layer Meteor, 116, 395-421.

Kondo, J., 1975: Air-sea bulk transfer coefficients in diabatic conditions. Bound.-Layer Meteor, 9, 91-112.

Kondo, J., and H. Yamazawa, 1986: Bulk transfer coefficient over a snow surface. Bound.-Layer Meteor, 34, 123-135.

Kusaka, H., H. Kondo, Y. Kikegawa, and F. Kimura, 2001: A simple single-layer urban canopy model for atmospheric models: Comparison with multi-layer and slab models. Bound.-Layer Meteor., 101, 329-358.

Kusaka, H., K. Nawata, A. Suzuki-Parker, Y. Takane, and N. Furuhashi, 2014: Mechanism of precipitation increase with urbanization in Tokyo as revealed by ensemble climate simulations. J. Appl. Meteor. Climatol., 53, 824-839.

Kusaka, H., A. Suzuki-Parker, T. Aoyagi, S. A. Adachi, and Y. Yamagata, 2016: Assessment of RCM and urban scenarios uncertainties in the climate projections for August in the 2050s in Tokyo. Climatic Change, 137,
427-438.

Lemonsu, A., R. Kounkou-Arnaud, J. Desplat, J.-L. Salagnac, and V. Masson, 2013: Evolution of the Parisian urban climate under a global changing climate. Climatic Change, 116, 679-692.

Lin, C.-Y., C.-J. Su, H. Kusaka, Y. Akimoto, Y.-F. Sheng, J.-C. Huang, and H.-H. Hsu, 2016: Impact of an improved WRF urban canopy model on diurnal air temperature simulation over northern Taiwan. Atmos. Chem. Phys., 16, 1809-1822.

Martilli, A., A. Clappier, and M. W. Rotach, 2002: An urban surface exchange parameterisation for mesoscale models. Bound.-Layer Meteor., 104, 261-304.

Masson, V., 2000: A physically-based scheme for the urban energy budget in atmospheric models. Bound.-Layer Meteor, 94, 357-397.

Mori, K., and T. Sato, 2015: Evaluating the role of snow cover in urban canopy layer on the urban heat island in Sapporo, Japan with a regional climate model. $J$. Meteor. Soc. Japan, 93, 581-592.

Nakamura, T., O. Abe, H. Nakamura, M. Higashiura, and N. Numano, 1984: Comparison of the roof snow depth on three different types of buildings with the ground snow depth. Research Report on National Research Center for Disaster Prevention, 32, 55-72 (in Japanese with English abstract).

Nakanishi, M., and H. Niino, 2004: An improved MellorYamada level-3 model with condensation physics: Its design and verification. Bound.-Layer Meteor., 112, $1-31$.

Nemunaitis-Berry, K. L., P. M. Klein, J. B. Basara, and E. Fedorovich, 2017: Sensitivity of predictions of the urban surface energy balance and heat island to variations of urban canopy parameters in simulations with the WRF model. J. Appl. Meteor. Climatol., 56, 573-595.

Saito, K., T. Fujita, Y. Yamada, J. Ishida, Y. Kumagai, K. Aranami, S. Ohmori, R. Nagasawa, S. Kumagai, C. Muroi, T. Kato, H. Eito, and Y. Yamazaki, 2006: The operational JMA nonhydrostatic mesoscale model. Mon. Wea. Rev., 134, 1266-1298.

Saito, K., J. Ishida, K. Aranami, T. Hara, T. Segawa, M. Narita, and Y. Honda, 2007: Nonhydrostatic atmospheric models and operational development at JMA. J. Meteor. Soc. Japan, 85B, 271-304.

Sasaki, H., K. Kurihara, I. Takayabu, and T. Uchiyama, 2008: Preliminary experiments of reproducing the present climate using the non-hydrostatic regional climate model. SOLA, 4, 25-28.

Shinojima, K., 1967: Study on the visco-elastic deformation of deposited snow. Phys. Snow Ice, 1, 875-907.

Shui, T., J. Liu, P. Zhang, S. Liu, and Z. Zhao, 2016: Development of an urban canopy model for the evaluation of urban thermal climate with snow cover in severe cold regions. Build. Environ., 95, 160-170.

Sturm, M., J. Holmgren, M. König, and K. Morris, 1997: 
The thermal conductivity of seasonal snow. J. Glaciol., 43, 26-41.

Takeuchi, Y., Y. Kodama, N. Ishikawa, and D. Kobayashi, 1993: The effect of snow cover on the thermal characteristics of the surface layer. Low Temp. Sci., 51A, 63-76 (in Japanese with English abstract).

Valeo, C., and C. L. I. Ho, 2004: Modelling urban snowmelt runoff. J. Hydrol., 299, 237-251.

Yabu, S., S. Murai, and H. Kitagawa, 2005: Clear-sky radiation scheme. Report of Numerical Prediction Division
(Suuchiyohouka Houkoku Bessatsu Houkoku), 51, 5364 (in Japanese).

Yamazaki, T., 2001: A one-dimensional land surface model adaptable to intensely cold regions and its applications in Eastern Siberia. J. Meteor. Soc. Japan, 79, 1107-1118.

Yamazaki, T., T. Sakuraoka, T. Nakamura, and J. Kondo, 1991: A study of snow metamorphism: I Model description. Seppyo, 53, 115-123 (in Japanese with English Abstract). 